OPEN ACCESS

Edited by:

Jun Deng,

Shanghai Cancer Institute, China

Reviewed by:

Stefania Croci,

Local Health Authority of Reggio

Emilia, Italy

Yannick van Sleen,

University Medical Center Groningen,

Netherlands

Jian-long Guan,

Fudan University, China

Lindi Jiang,

Fudan University, China

${ }^{*}$ Correspondence:

Cornelia M. Weyand cweyand@stanford.edu

Specialty section: This article was submitted to Autoimmune and

Autoinflammatory Disorders,

a section of the journal

Frontiers in Immunology

Received: 25 October 2020 Accepted: 24 December 2020

Published: 25 February 2021

Citation:

Akiyama M, Ohtsuki S, Berry GJ, Liang DH, Goronzy JJ and Weyand CM (2021)

Innate and Adaptive Immunity in Giant Cell Arteritis.

Front. Immunol. 11:621098. doi: 10.3389/fimmu.2020.621098

\section{Innate and Adaptive Immunity in Giant Cell Arteritis}

\author{
Mitsuhiro Akiyama ${ }^{1}$, Shozo Ohtsuki ${ }^{1}$, Gerald J. Berry ${ }^{2}$, David H. Liang ${ }^{1}$, Jörg J. Goronzy ${ }^{1}$ \\ and Cornelia M. Weyand ${ }^{1 *}$ \\ ${ }^{1}$ Department of Medicine, Stanford University School of Medicine, Stanford, CA, United States, ${ }^{2}$ Department of Pathology, \\ Stanford University School of Medicine, Stanford, CA, United States
}

Autoimmune diseases can afflict every organ system, including blood vessels that are critically important for host survival. The most frequent autoimmune vasculitis is giant cell arteritis (GCA), which causes aggressive wall inflammation in medium and large arteries and results in vaso-occlusive wall remodeling. GCA shares with other autoimmune diseases that it occurs in genetically predisposed individuals, that females are at higher risk, and that environmental triggers are suspected to beget the loss of immunological tolerance. GCA has features that distinguish it from other autoimmune diseases and predict the need for tailored diagnostic and therapeutic approaches. At the core of GCA pathology are $\mathrm{CD} 4^{+} \mathrm{T}$ cells that gain access to the protected tissue niche of the vessel wall, differentiate into cytokine producers, attain tissue residency, and enforce macrophages differentiation into tissue-destructive effector cells. Several signaling pathways have been implicated in initiating and sustaining pathogenic $\mathrm{CD} 4^{+} \mathrm{T}$ cell function, including the NOTCH1-Jagged1 pathway, the CD28 co-stimulatory pathway, the PD-1/PD-L1 co-inhibitory pathway, and the JAK/STAT signaling pathway. Inadequacy of mechanisms that normally dampen immune responses, such as defective expression of the PD-L1 ligand and malfunction of immunosuppressive $\mathrm{CD}^{+} \mathrm{T}$ regulatory cells are a common theme in GCA immunopathology. Recent studies are providing a string of novel mechanisms that will permit more precise pathogenic modeling and therapeutic targeting in GCA and will fundamentally inform how abnormal immune responses in blood vessels lead to disease.

Keywords: T cell, macrophage, vasculitis, NOTCH, endothelial cell, PD-L1, CD8 Treg, exosome

\section{INTRODUCTION}

Giant cell arteritis (GCA), also known as "temporal arteritis," is an autoimmune disease that exclusively affects the elderly host (1). The disease preferentially involves the thoracic aorta and its major branch vessels, including the temporal artery and vessels supplying the optic nerve and the retina. Accordingly, the clinical manifestations of GCA include life-threatening complications, such as aortic dissection, aortic aneurysm, and blindness due to ischemia of the optic nerve. Globally, the highest incidence rates of GCA occur in Northern Europe, including Iceland, Norway, Sweden, and Denmark. High disease risk in Northern European populations has supported the concept that both genetic and environmental factors shape disease susceptibility. Genome-wide association studies 
have confirmed earlier data that polymorphisms in the major histocompatibility complex (MHC), specifically the Human leukocyte antigen (HLA)-DR region confers the highest risk $(2,3)$. Amongst non-HLA regions, PLG and P4HA2 appear to play a role as risk determinants (Table 1) (4). PLG (plasminogen) and P4HA2 (Prolyl 4-hydroxylase subunit alpha-2) are involved in vascular remodeling and neoangiogenesis, suggesting relevance of these processes in GCA pathogenesis. Of interest, a distinct set of genetic polymorphisms have been implicated in Takayasu arteritis (TAK) $(5,6)$, an autoimmune large vessel vasculitis that shares many similarities with GCA but preferentially affects young Asian women. In TAK, HLA-B has been shown to have the strongest disease association (Table 1). Like in GCA, patients with TAK have enrichment of genetic polymorphism in non-HLA regions; include such functionally related to activation of cytotoxic lymphocytes, e.g. natural killer cells and $\mathrm{CD}^{+} \mathrm{T}$ cells. Differences in disease risk genes in GCA and TAK indicate that different pathomechanisms may contribute to autoimmune and auto-inflammatory diseases of the large arteries (7-9).

The vasculitic lesions of GCA are composed of tissueinfiltrating and tissue-resident innate and adaptive immune cells; mostly, $\mathrm{CD}^{+} \mathrm{T}$ cells, dendritic cells, macrophages, histiocytes, and multinucleated giant cells $(10,11)$ (Figure 1). Recent advances in understanding the pathogenesis of GCA have provided important insights into disease-inducing and -sustaining mechanisms. Key pathogenic elements include a

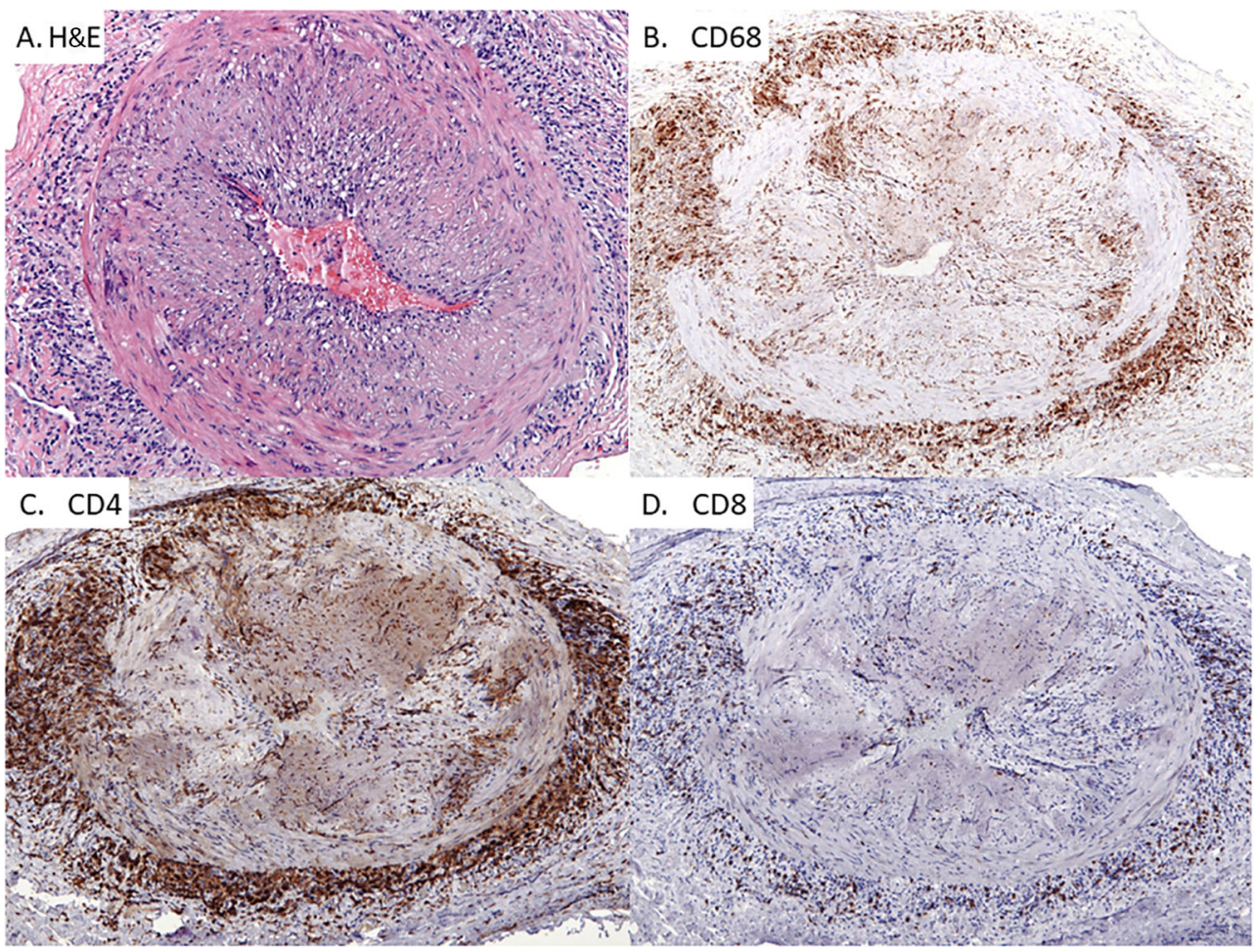

FIGURE 1 Giant Cell Arteritis in the Temporal Artery. Classic histopathologic and immunophenotypic findings of temporal arteritis in a 78-year old woman presenting with headaches. Panel (A) Transmural arterial inflammation with marked luminal narrowing caused by intimal proliferation which creates a slit-like lumen. Multinucleated giant cells are concentrated in the medial layer (H\&E x125) Panel (B) CD68-positive histiocytes accumulating within the medial and adventitial layers of

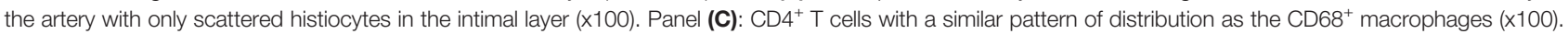
Panel (D) Infrequent CD8 ${ }^{+} T$ cells within the T cell infiltrates (x100).

TABLE 1 | Gene regions associated with large vessel vasculitis.

\begin{tabular}{|c|c|c|c|}
\hline Reported year & Population & The number of participants & Gene region \\
\hline 2017 & European ancestries & $\begin{array}{l}2134 \text { GCA patients } \\
9125 \text { controls }\end{array}$ & HLA-DRA/HLA-DRB1, PLG, P4HA2 \\
\hline 2018 & Japan & $\begin{array}{l}415 \text { TAK patients } \\
2170 \text { controls }\end{array}$ & HLA-B, FCGR3A, IL12B, DUSP22, PTK2B, KLHL33, LILRA3, chr21q22 \\
\hline 2015 & Turkey and North America & $\begin{array}{l}693 \text { TAK patients } \\
1536 \text { controls }\end{array}$ & HLA-B/MICA, IL6, RPS9/LILRB3, chr21q22 \\
\hline
\end{tabular}


vascular and an extravascular disease component, with sitespecific immune processes relevant for disease inside and outside of the vascular wall. Also, it is now appreciated that the vessel wall has unique structural barrier features that make it an immuno-privileged tissue site, protecting it from unwanted immune responses. Breakdown of this immune privilege require aggressive immune responses that first must overcome the natural protection inherent to life-sustaining arteries. Studies of persistent vasculitis in GCA patients have stressed the autonomy of tissue-residing inflammatory infiltrates, building significant challenges for the elimination of vascular wall inflammation. Another hurdle in treating GCA relates to the functional heterogeneity of vasculitic effector cells, which lends stability to the inflammatory lesions and renders them resistant to targeted immunosuppression. The granulomatous nature of the vessel wall lesion has nurtured discussions that infectious microorganisms may serve as the vasculitogenic antigen, but reproducible data implicating a viral or bacterial antigen are missing (9). Other environmental triggers, such as air pollutants etc are insufficiently explored. The extravascular component of GCA is poorly understood. Clinically and diagnostically, it is characterized by intense acute phase responses, resulting in elevated Erythrocyte Sedimentation Rate (ESR) and C-reactive protein (CRP). Patients also complain about constitutional symptoms and proximal myalgias that are promptly responsive to glucocorticoids and the recently approved anti-interleukin (IL)-6 receptor antibody tocilizumab (12). However, fluctuations in acute phase reactants, as captured by measurement of ESR and CRP, can occur despite persistence of vessel wall inflammation (13). The lack of reliable disease biomarkers capturing vessel wall inflammation is problematic in managing GCA.

The present review will focus on recent advances in understanding the dysfunctional innate and adaptive immune responses that cause autoimmune vasculitis, with a focus on how the arterial wall immuno-privilege is broken, how vascular inflammation is sustained and how abnormal immunity maintains vascular remodeling. Progress in understanding pathogenic cascades will inevitably broaden the therapeutic armamentarium that is so urgently needed to improve management of vasculitis.

\section{INNATE IMMUNITY IN GCA}

\section{Monocytes and Macrophages as Disease Drivers in GCA}

The three-layered walls of the muscular and elastic arteries are free of inflammatory cells and protected by immune privilege. Inaccessible tissue sites, e.g. in the testis and the eye, prioritize the integrity of life-sustaining organs over localized immunity. Maintenance of such privileged sites involve a combination of mechanisms, including physical barriers, lack of antigenpresenting cells and counter regulatory processes dampening immune stimulation. In the case of GCA, the immune privilege is lost and both, innate as well as adaptive immune cells enter the privileged site (Figure 1). In the three-layered arteries, composed of the intimal layer, the medial smooth muscle cell layer and the supportive adventitial layer, access to the vessel wall occurs through the adventitial vasa vasorum network.

Recent work has described a molecular defect in circulating blood monocytes from GCA patients, which endows these cells with tissue invasive capabilities. Specifically, GCA monocytes spontaneously produce high amounts of the metalloproteinase MMP-9 and digest the basement membrane to overcome the barrier between vasa vasora capillaries and extracellular tissue. By blocking the proteinase activity of MMP-9 with a monoclonal antibody, Watanabe et al (14). implicated GCA monocytes in the breakdown of the basement membrane and in paving the way for both innate and adaptive immune cells into the wall (Figure 2). Remarkably, T cells failed to invade the tissue site unless they were accompanied by MMP-9-producing monocytes. Besides MMP-9, GCA monocytes produced high amounts of MMP-2 and -7 transcripts, while MMP-1, $-3,-8,-10$, or -12 transcripts were indistinguishable in GCA and control monocytes. Metalloproteinases are critically important in several physiologic and pathologic processes $(15,16)$ and it likely that inappropriate MMP-9 production is not an exclusive problem in GCA. However, the upregulation of MMP-9 already in monocytes clearly distinguishes GCA patients from healthy individuals.

Once circulating monocytes have differentiated into macrophages, the propensity to produce excess MMP-9 continuously is a distinguishing feature of macrophages that reach the adventitial and medial layer of the artery (14). Also, multinucleated giant cells (MNG), the hallmark cell of GCA lesions, have a particularly strong signal for MMP-9, indicating that the metalloproteinase critically affects events that lead to the formation and the destructive potential of the granulomatous lesions (Figure 2). A typical feature of GCA is the thinning of the medial layer, presumably by injuring vascular smooth muscle cells and the fragmentation of the elastic laminae that separate the media from the intima. Here, local delivery of MMP-9 by tissue-invasive monocytes/macrophages emerges as a pinnacle event. The media of a healthy artery is essentially impenetrable, a barrier that must be overcome by pathogenic macrophages endowed with MMP-9-dependent elastolytic and gelatinolytic activities $(17,18)$. Thus, abnormal programming of monocytes represents an upstream disease element, facilitating initial entrance and maneuvering of inflammatory cells in the arterial wall. This pathomechanism may be particularly important in the aorta of GCA patients, prone to dissection and aneurysm formation (Figure 3).

How aberrant MMP-9 production in GCA monocytes and macrophages is induced has remained unresolved, but this is a defect that is a prerequisite of disease and is present early in the disease process. MMP-9 continues to participate in the granulomatous inflammation in established and in late disease (Figure 2). The aberrant production of MMP-9 in monocytes and macrophages of GCA patients seems to be combined with upregulation of MMP-2, suggesting a coordinated pathomechanism that affects families of enzymes $(14,19)$.

Macrophage populations that settle in the granulomatous lesions are highly heterogenous. Early studies have given rise 


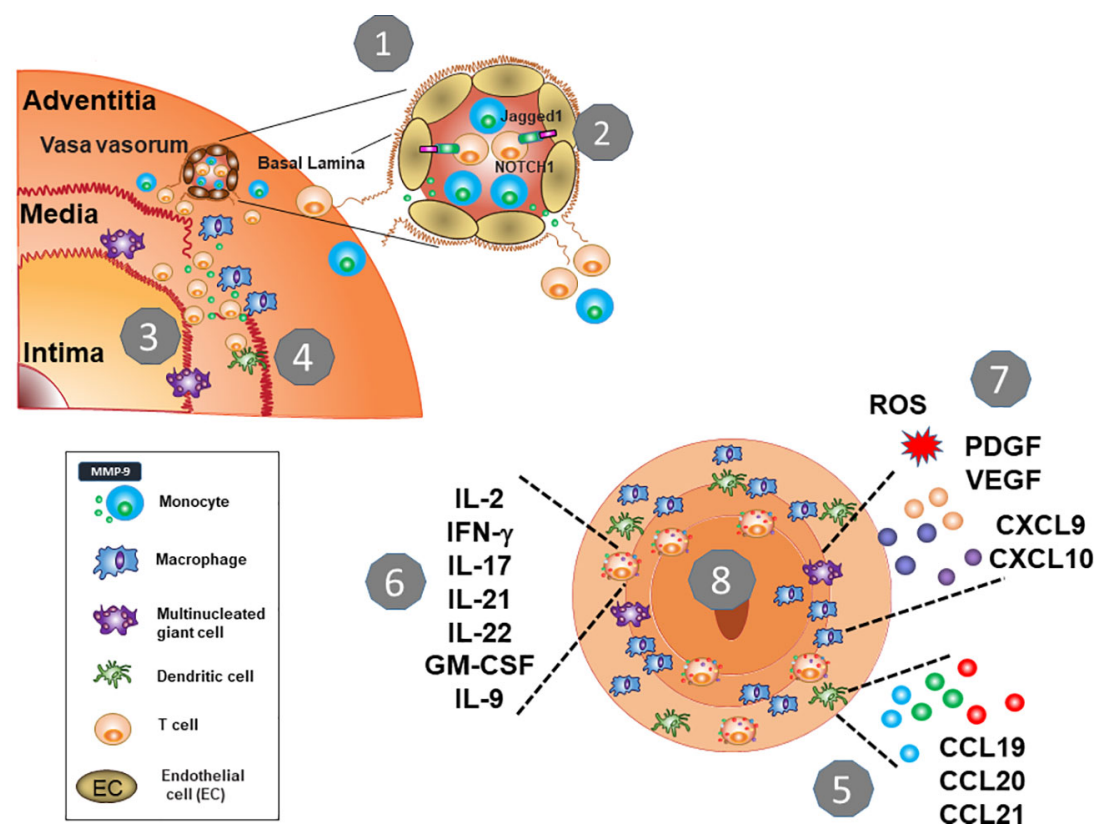

FIGURE 2 | Key Pathogenic Steps in Giant Cell Arteritis. 1. The protective shield of the artery wall breaks when immune cells leave the vasa vasorum and invade into the tissue. An essential checkpoint is the digestion of the vascular basal lamina, facilitated by MMP-9-producing monocytes. 2. Vasculitic T cells follow, and macrophages (histocytes) and T cells form granulomatous infiltrates in the adventitia and media. 3. MMP-9-producing macrophages destructs the elastic laminae and eventually, tissue-damaging multinucleated giant cells emerge. 4. T cells encounter DC that lack the immunoinhibitory ligand PD-L1 and enter unopposed and persistent activation. 5. Wall-residing DC provide chemokines and cytokines to enhance immune cell recruitment. $\mathbf{6}$. Chronically stimulated T cells differentiate into multifunctional effector cells providing an array of effector cytokines. They also acquire tissue residence and replenish the lesion from within. 7. Macrophages are functionally heterogenous, but their functional commitment is directly related to their positioning in the vessel wall. Macrophage products include chemokines and cytokines, tissue-damaging mediators (ROS, MMP-9) as well as growth factors (VEGF, PDGF). 8. Continuously stimulated T cells and macrophages elicit a maladaptive response-to-injury presenting as vessel wall remodeling, with wall vascularization and intimal hyperplasia.

to the concept that geographical mapping of the macrophages and functional commitment are linked. Macrophages in the media and at the media-intima border are most disease relevant. The fragmentation of the lamina elastica interna, the formal landmark separating the vascular smooth muscle cell (VSMC)-rich media from the intima, remains a hallmark of disease. The tissue-destructive potential of medial macrophages rests on the production of MMP-9, but also on the release of reactive oxygen species (ROS) (20). The tissue-damaging features of medial macrophages are counterbalanced by their ability to provide growth factors and angiogenic cytokines (Figure 2). Platelet-derived growth factor (PDGF)-producing macrophages and multinucleated giant cells sitting at the fragmented elastic lamina are critically important in driving the wall remodeling process, including the growth of neointima (21). Several cell types, including myofibroblasts, dedifferentiated VSMCs, and mesenchymal stem cells fuel the formation of the neo-tissue that occupies the artery's lumen and blocks blood flow (22). PDGF has been implicated in facilitating proliferation and directed migration of precursor cells. This maladaptive wound healing process is only possible with sufficient neoangiogenic activity. While intramural vessels are usually restricted to the adventitia, inflamed temporal arteries contain networks of newly formed capillaries, penetrating the media as well as the intima (21). Here, macrophage-derived vascular endothelial growth factor (VEGF) is instrumental in providing a potent growth factor for endothelial cells (23). Interestingly, multinucleated giant cells possess the ability to synthesize VEGF. VEGF is elevated markedly in the circulating blood of GCA patients (24-26), where this angiogenesis factor functions as a regulator of endothelial cells and promotes endothelial cell-T cell interaction (24). However, the precise cellular source of the circulating VEGF in GCA patients has not been determined. A close correlation between tissue site and macrophage functional commitment in the vasculitic lesions has recently been confirmed by Jiemy et al, who showed that MMP $-9^{+}$macrophages were placed at areas of tissue destruction, while $\mathrm{FR} \beta+$ macrophages were positioned in the hyperplastic intima (27).

GCA is not the only vasculitis in which macrophages are key pathogenic effector cells. Rather, accumulation of highly activated macrophages in the disease lesions is a feature of other granulomatous diseases, including the small vessel vasculitis granulomatosis with polyangiitis (GPA). Specifically, overrepresentation of MMP-9 producing macrophages appears to be common between GCA and GPA (28). GPA is an autoimmune vasculitis of small blood vessels, typically associated with tissue destruction due to granuloma formation. Neutrophils forming neutrophil extracellular traps (NETs) are 

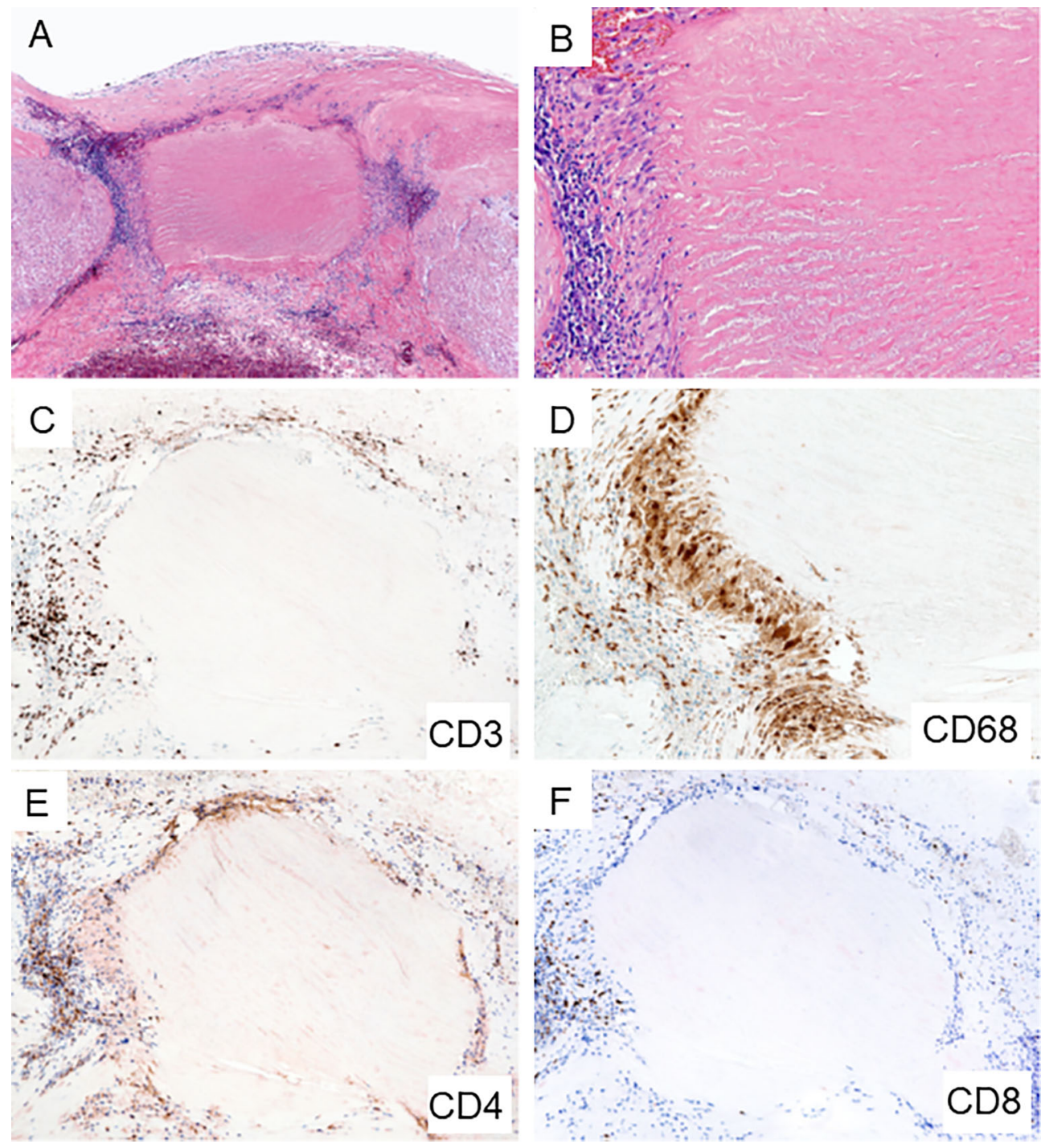

FIGURE 3 | Giant Cell Arteritis in the Aorta. Biopsy sample from surgically removed aortic wall of a patient undergoing emergency aortic repair. (A, B) Hematoxylin and eosin staining showing typical granulomatous inflammation with rings of predominantly lymphocytes and macrophages around necrotic medial tissue (A x60; $\mathrm{B} \times 200)$. (C) $\mathrm{CD}^{+} \mathrm{T}$ cells form a collarette of inflammation enclosing the necrotic aortic wall (x100). (D) CD68 ${ }^{+}$histiocytes palisade at the edge of the damaged tissue (x200). (E) CD4 ${ }^{+} T$ cells are the dominant T cell subset within the granulomatous infiltrates (x100). (F) Infrequent CD8 ${ }^{+} \mathrm{T}$ cells in the aortic wall (x100).

believed to function as an inflammatory nidus. In a subset of GPA patients the disease predominantly manifests in the head and neck $(\mathrm{H} \& \mathrm{~N})$, presenting with bony erosions of the orbital and sinus walls, septal perforations, saddle-nose deformities, middle ear damage and epiglottitis, all related to uncontrolled destruction of bone, cartilage, and connective tissues. In mechanistic studies, NETs released from H\&N GPA neutrophils functioned as powerful stimulators of macrophages, inducing MMP-9 production (28). Such MMP-9 high-producing macrophages possess tissuedestructive capabilities (28), and MMP-9-producing macrophages and multinucleated giant cells dominate the granulomatous tissue infiltrates in naso-sinal biopsies from H\&N GPA patients (28). These data implicate degradation of collagen IV in basement membranes and digestion of extracellular matrix in the pathologic events leading to GPA.

Given the similarities in GCA and GPA, dysregulation of MMP-9 production may be a fundamental pathomechanism, shared amongst vasculitides and shared by diseases with granulomatous inflammation. So far, none of the genetic polymorphisms predisposing to either GCA or GPA have been connected to the functional domain of metalloproteinases.

Macrophages from GCA patients have been functionally compared to those of another vasculopathy, namely coronary artery disease (CAD). CAD is now accepted as an inflammatory blood vessel condition that progresses over decades and causes the formation of atherosclerotic plaques in the subendothelial 
space of susceptible arteries (29). In the atherosclerotic plaque, highly activated macrophages take up deposited lipoproteins and modified lipids to transform into the pathognomonic foam cells. Giant cell formation occurs in just a subset of patients with atherosclerotic lesions. Thus, in GCA and CAD macrophages perform fundamentally different functions. Comparison of monocytes and monocyte-derived macrophages from GCA and CAD patients has demonstrated that these myeloid cells have distinct molecular signatures. $\mathrm{CAD}$ macrophages are prone to produce high amounts of inflammatory cytokines, such as IL-1 $\beta$ and IL-6, even more so than GCA macrophages (30). Another distinguishing features between the two diseases is the expression of the co-inhibitory ligand PD-L1, which is distinctly low in GCA, but high in CAD (30). Notably, macrophages from both patient populations abundantly produced chemokines (CXCL9, CXCL10), supporting a role in cell recruitment and assembly of the vessel wall lesions (Figure 1B). Metabolic conditioning was identified as the underlying mechanism. While CAD macrophages were programmed to uptake and utilize glucose, this was not the case for GCA macrophages. Addiction to glucose is one of the driving forces in $\mathrm{CAD}$ macrophages, dictating the dynamics of the glycolytic pathway, the setting of mitochondrial activity, the production of reactive oxygen species and ultimately, the secretion of IL-6 (31). The low glycolytic activity in GCA monocytes may be part of a broader metabolic program, as fasting blood glucose, cholesterol and triglyceride levels have been described to be negatively associated with the development of giant cell arteritis (32).

In summary, "trained immunity" in GCA leads to monocyte instruction, changing their metabolic circuitry and their functional differentiation. The concept of "trained immunity" is well understood in non-vasculitic cardiovascular disease (33-36) and relates to the concept that monocytes, macrophages, dendritic cells, and NK cells can be imprinted by encountering inflammatory stimuli, undergoing a priming process that changes their response to subsequent challenges. It is now recognized that the "training" is imprinted into the epigenome. In GCA monocytes, a lead abnormality is the high expression of MMP-9, a protease that takes center stage when inflammatory cells leave the blood stream and enter the "forbidden territory" of the vessel wall. Also affected is the expression of co-inhibitory ligands and the commitment to cytokine production. The training of monocytes has profound consequences for their later life as macrophages. They continue to produce MMP-9, now enabling them to destroy the tissue microenvironment. Functional analysis of lesional macrophages has emphasized their tissue repair capabilities, including the production of growth and angiogenesis factor, all promoting the maladaptive remodeling process in the GCA-affected artery (Figure 2).

\section{Vascular Dendritic Cells (DC) as Presenters of Vasculitogenic Antigens}

DCs are part of the innate immune system and are indispensable for the induction of adaptive immune responses. Specifically, DCs are needed to present antigen for $\mathrm{T}$ cell priming and are thought to be the principal initiators of $\mathrm{T}$ cell immunity $(37,38)$.
Besides their role in presenting exogenous antigens, such as microbial antigens and allergens, DCs are also instrumental in the handling of self-antigens and thus determine the fate of autoreactive $\mathrm{T}$ cells. In addition, activated DCs are an important source of cytokines and chemokines, orchestrating the assembly of inflammatory infiltrates. Finally, they finetune T cell activation by providing both co-stimulatory and co-inhibitory signals for $\mathrm{T}$ cells $(37,38)$. Critically involved in activating naïve T cells, DCs function in secondary lymphoid organs, such as lymph nodes and the bone marrow. In the case of medium and large arteries, they possess their own tissue residing DCs, so-called vasDCs (39, 40) (Figure 4). Such vasDCs are believed to have two disease relevant functions in GCA; (a) guarding the vessel wall immune privilege, possibly by providing tolerogenic signals, and (b) presenting vasculitogenic antigens in the vessel wall infiltrates $(39,40)$. Healthy temporal arteries possess vasDCs positioned at the adventitia-media junction (Figure 4). In the inflamed artery, DCs may move into other tissue niches to join macrophages in presenting antigen to $\mathrm{T}$ cells that are distributed throughout the vessel wall. vasDCs placed in the granulomatous infiltrates produce chemokines, such as CCL19, 20, and 21, and strongly express the co-stimulatory molecule CD86 (41-43) (Figure 5). The disease relevance of the CD28-CD86 co-stimulatory pathway was recently demonstrated in a study exploring CD28-blocking antibodies (44). Lesional T cells were found to be dependent on CD28-mediated co-stimulation, even more so than normal control T cells. Blocking the CD28-CD86 receptor ligand interaction had profound inhibitory effects on the vasculitic process (44). Not only was co-stimulation relevant in determining the strengths of $\mathrm{T}$ cell activation, it regulated the amount of pro-inflammatory effector cytokines produced in the vasculitic lesions. Most importantly, inflammation-induced remodeling of the vessel wall, involving intimal hyperplasia and neoangiogenesis, required crosslinking of CD28 by CD80/ CD86 (44). Taken together, by controlling in situ co-stimulatory signals, vasDC ultimately shape several dimensions of the vasculitic process (Figures 2 and 4 ).

The dynamics and intensities of $\mathrm{T}$ cell activation not only depend on co-stimulation but are equally shaped by coinhibitory signals. In healthy arteries, vasDC express the inhibitory ligand PD-L1, effectively dampening $\mathrm{T}$ cell triggering. It is now recognized that a defect in this coinhibitory pathway is a hallmark of GCA (45). Specifically, DC-Sign $^{+}$vasDC in healthy temporal arteries not only express CD80/CD86, but also PD-L1 (Figures 2 and 5). Crosslinking of the $\mathrm{PD}-1$ receptor on $\mathrm{T}$ cells may indeed be one of the mechanisms through which vasDC protect the tissue niche and interrupt in situ immune activation. In GCA, vasDC lack PD-L1, suspending a negative feedback mechanism that halts inappropriate $\mathrm{T}$ cell stimulation. The $\mathrm{PD}-\mathrm{L} 1^{\mathrm{lo}}$ phenotype is shared amongst patient-derived DC and macrophages (30), indicating a fundamental breakdown of this important immune checkpoint. The lack of PD-L1 in inflamed arteries does not explain why essentially all $\mathrm{CD}^{+}{ }^{+} \mathrm{T}$ cells in the lesions are strongly positive for PD-1 (45). Possible explanations are that under physiologic conditions negative signaling induced by 


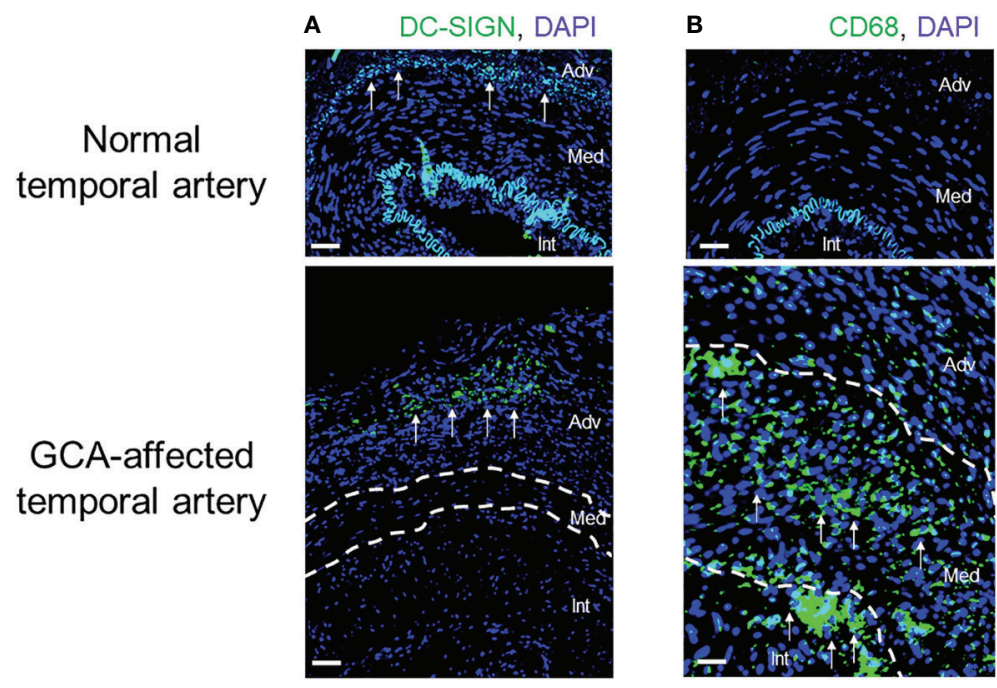

FIGURE 4 | Innate Immune Cells in Giant Cell Arteritis. Tissue sections from temporal artery biopsies were stained for the dendritic cell (DC) marker DC-SIGN (A) and the macrophage marker CD68 (B) and visualized by immunofluorescence imaging. Nuclei marked by DAPI. In the healthy artery, the autofluorescent lamina elastica interna separates the media and intima. DC-SIGN ${ }^{+}$dendritic cells are positioned at the adventitial-medial border. In the vasculitis-affected artery, DC-SIGN ${ }^{+}$ dendritic cells expand in the adventitia. CD68 ${ }^{+}$macrophages are essentially undetectable in the healthy artery but occupy all wall layers of the GCA artery. Int, intima; Med, media; Adv, adventitia. Scale Bar; $50 \mu \mathrm{m}$.

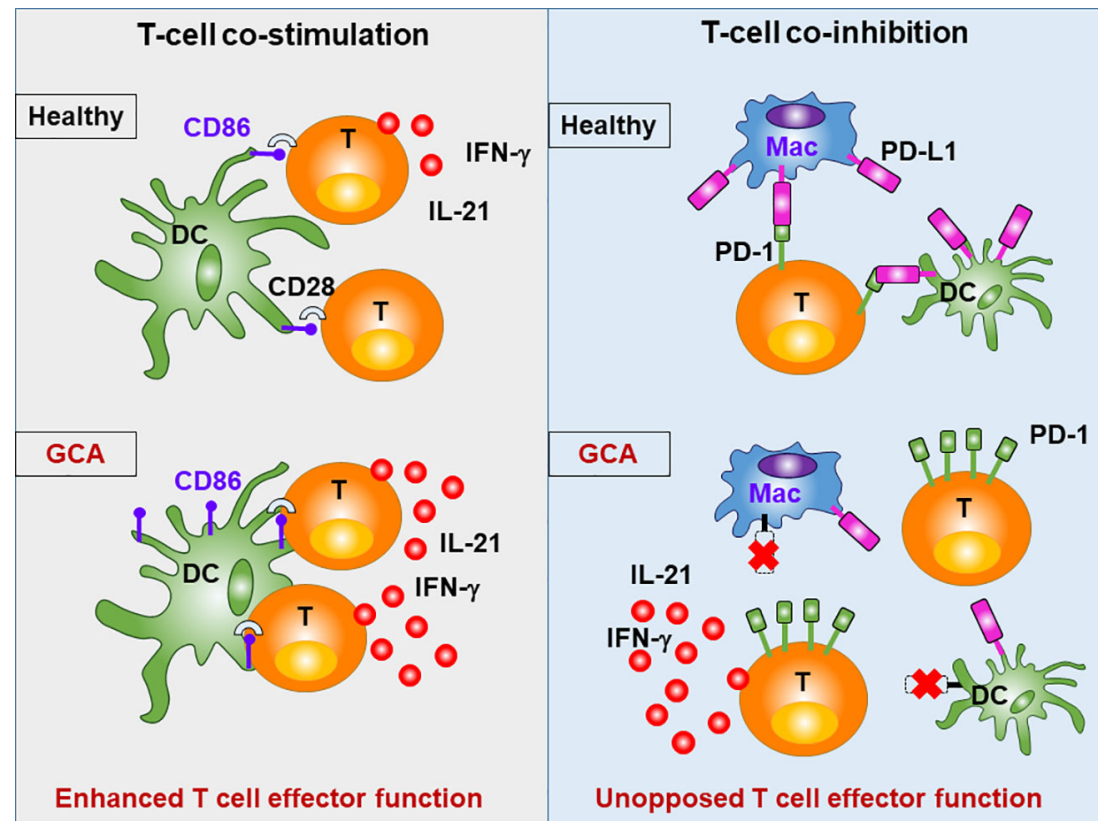

FIGURE 5 | Abnormal T cell Activation in GCA. The intensity and duration of adaptive immunity depends on the availability of specific antigen, but also on a mixture of positive (co-stimulatory) and negative (co-inhibitory) signals, that modulate the T cell receptor activation cascade. Patients with GCA have abnormalities in the CD28 co-stimulatory pathway and in the co-inhibitory PD-1/PD-L1 pathway, resulting in sustained and unopposed activation of pathogenic T cells. Under physiologic conditions, CD28 on T cells recognizes CD80/86 on antigen-presenting cells (e.g. dendritic cells; DC), prolonging and intensifying T cell activation. Signaling through this pathway is intensified in GCA. Under physiologic conditions, PD-1 on T cells recognizes PD-L1 on antigen presenting cells (e.g. macrophages; Mac), resulting in dampening of T cell activation. In GCA, PD-L1 is expressed at very low levels, disrupting this negative signal, and boosting T cell effector functions. 
tissue-expressed PD-L1 prevents access of T cells to the tissue niche and that this mechanism is defective in PD-L1 ${ }^{\text {lo }}$ hosts.

The PD-1/PD-L1 immune checkpoint is a critical regulator of immunity and is now one of the most important therapeutic targets in cancer patients (46). PD-1/PD-L1 deficiency in GCA has two clinically relevant consequences (47). First, excessive activity of this checkpoint is linked to insufficient anti-tumor immune responses. Tumors aberrantly express PD-L1 and utilize this mechanism to escape from anti-tumor T cell immunity. The defect of PD-1/PDL1 signaling in GCA and the excess of PD-1/PD-L1 signaling in cancer patients raises the question whether GCA patients have a natural protection from malignancy. Epidemiological studies support the concept that GCA patients die from cancer less than expected $(48,49)$. If the broken PD-1/PD-L1 checkpoint has beneficial effects for GCA patients, then therapeutic efforts to restore the checkpoint could be effective to inhibit vasculitis while enhancing the risk for malignancy. This is not a trivial consideration, given the advanced age and the age-related cancer risk in patients with GCA. Vice versa, weakening the PD-1/PD-L1 checkpoint is the therapeutic goal in the widespread application of checkpoint inhibitors in patients with malignancies. This therapeutic intervention should place the host at risk to develop vasculitis. In support of this concept, numerous case reports have described aggressive aortitis and vasculitis in checkpoint inhibitor treated individuals $(50,51)$. In a human artery-SCID mouse chimeric system, in which human arteries are engrafted into NSG mice and vasculitis is induced by adoptive transfer of peripheral blood mononuclear cells of GCA patients, injection of a PD-1 blocking antibody produced aggressive vessel wall inflammation and vascular remodeling (45). More importantly, healthy mononuclear cells were able to induce vasculitis, if the checkpoint was blocked. This mimics conditions in checkpoint inhibitor treated cancer patients and emphasizes the risk of such cancer patients to come down with iatrogenic vasculitis.

Recent data suggest that a second immunoinhibitory checkpoint involving V-domain Immuno-globulin-containing suppressor of $\mathrm{T}$ cell activation (VISTA) may be less functional in GCA (52). Hid Cadina et al. have reported that VISTA+ Th cells are reduced in the blood of GCA patients but enriched in the inflamed temporal arteries.

Taken together, DC and other antigen-presenting cells make critical contributions to GCA, not only by in situ antigen presentation, but by distorting the threshold settings for $\mathrm{T}$ cell activation (Figures 2, 4 and 5). GCA DC drive vasculitis by expressing CD86, amplifying disease-relevant enhancement of T cell immunity. At the same time, they fail to dampen lesional $\mathrm{T}$ cells by lacking PD-L1 on their surface. PD-L1 ${ }^{\text {lo }} \mathrm{DC}$ allow tissue entrance and persistence of highly activated effector T cells. The disbalance between robust co-stimulation and ineffective coinhibition sets the stage for uncontrolled $\mathrm{T}$ cell immunity, with all the sequelae of a maladaptive response-to-injury. This scenario also presents an untapped therapeutic opportunity: treating GCA by interrupting excess co-stimulation or by reinstating co-inhibition (Figure 5). To which degree DC participate in the extravascular disease pathways of GCA is currently unknown. It is possible that DC in the circulation or in non-vascular tissues also have disease relevance and that they collude with abnormal $\mathrm{T}$ cells to render individuals susceptible to vasculitis (40).

\section{Other Innate Cell Types}

Other types of innate immune cells, such as neutrophils, eosinophils and NK cells are typically scarce or absent in the vasculitic lesions of GCA (53). Indeed, eosinophilic inflammation should prompt the search for an alternative diagnosis, such as eosinophilic granulomatosis with polyangiitis. In rare cases, temporal arteritis can be attributed to an alternative vasculitis and atypical features on histologic examination are often the first clue $(54,55)$. Neutrophils may have a role in extravascular GCA. In the peripheral blood of GCA patients, decrease of suppressor neutrophils has been reported to accelerate effector $\mathrm{T}$ cell proliferation (56). GCA shares with other vasculitides the presence of immature neutrophils in the peripheral blood, which tightly correlated with inflammatory activity. In an in vitro co-culture system, such immature neutrophils produced abundant reactive oxygen species that caused protein damage and injured the endothelial barrier permeability (57). Mast cells may play an active role in vessel wall inflammation and have been described as one of the cellular sources of VEGF in temporal arteritis lesions (58).

\section{ADAPTIVE IMMUNITY IN GCA}

GCA is an HLA class II associated disease and the dominant cell type in the vasculitic lesions are $\mathrm{CD} 4^{+} \mathrm{T}$ cells, moving the adaptive immune system into center stage (Figures $\mathbf{1}$ and $\mathbf{3}$ ). Immunophenotyping of inflamed arteries demonstrates that $\mathrm{CD}^{+} \mathrm{T}$ cells outnumber $\mathrm{CD}^{+} \mathrm{T}$ cells (Figures $\mathbf{1}$ and $\mathbf{3}$ ), a feature which distinguishes GCA and Takayasu arteritis (9). In line with the observation that HLA class I molecules seem to be important as disease risk markers in Takayasu arteritis, the cytotoxic functions of $\mathrm{CD}^{+} \mathrm{T}$ cells have been implicated as a relevant disease mechanism in this vasculitis (9). However, recent data have assigned a disease relevant role to $\mathrm{CD}^{+} \mathrm{T}$ cells in the periphery. Specifically, $\mathrm{CD} 8^{+} \mathrm{T}$ cells with regulatory function, $\mathrm{CD}^{+}$Treg cells, are defective in GCA patients, failing to dampen $\mathrm{CD} 4^{+} \mathrm{T}$ cell function in vasculitis $(59,60)$.

Granulomatous infiltrates are typically composed of $\mathrm{CD} 4^{+} \mathrm{T}$ cells and macrophages and contain few B cells (61). Accordingly, autoantibodies seem to play no role in GCA. Cellular accumulations reminiscent of tertiary lymphoid aggregates, including B cells and plasma cells, have been seen in GCA affected aortic tissues (62). Whether they have functional relevance remains to be determined, but $B$ cells are not recognized as drivers of the typical granulomatous reaction causing GCA. It is to be expected that systemic inflammation and the acute phase reaction typical for extravascular GCA leads to shifts in the distribution of circulating B cells (63). However, the biological relevance is unknown.

Sharing of $\mathrm{T}$ cell receptor sequences in independent tissues sites affected by GCA has nurtured the concept that antigen 
recognition is central in the emergence of the granulomatous lesions $(64,65)$. The nature of a causative antigen, however, has remained speculative. A tempting speculation is the proposal to implicate viral infections. Elderly individuals harbor a spectrum of chronic viral infections and the immune aging process makes them more susceptible to reactivation (66). Thus, it has been proposed that varicella zoster may be the underlying trigger of GCA, but carefully designed studies have refuted this theory (6769). Recent observations that cancer patients treated with immune checkpoint inhibitors are at high risk to develop therapy-induced vasculitis $(9,50,51)$ have emphasized the role of antigen-nonspecific mechanisms. If unleashed, polyclonal $\mathrm{T}$ cell populations appear to be able to promote vasculitis.

At the current stage of knowledge, $\mathrm{T}$ cells in GCA patients make several mistakes that culminate in loss of tolerance and the establishment of chronic-persistent inflammatory infiltrates in the wall of susceptible arteries.

\section{Peripheral CD4+ T Cells in GCA Patients}

The hallmark abnormality in circulating $\mathrm{CD} 4^{+} \mathrm{T}$ cells from GCA patients is the aberrant expression of NOTCH1 $(24,70)$ (Figure 2). NOTCH1 is an oncogene, most notably, NOTCH1 mutations are present in the majority of patients with $\mathrm{T}$ cell acute lymphocytic leukemia (71). NOTCH signaling controls cell fate decisions and is needed for the specification of T cells; directs cell proliferation, differentiation, and cell death $(72,73)$. In GCA,
NOTCH1 expression on circulating $\mathrm{CD}^{+} \mathrm{T}$ cells has been implicated in enabling their transition from the blood into the tissue, representing a major tolerance defect in this disease. $\mathrm{CD}^{+} \mathrm{NOTCH}^{+} \mathrm{T}$ cells from GCA patients recognize aberrantly expressed JAGGED1 on the surface of vasa vasorum endothelial cells (24), facilitating their invasion into the vessel wall (Figure 2). Targeting the NOTCH1-JAGGED1 interaction was sufficient to suppress vasculitic activity (24), placing this receptor-ligand interaction at the top of GCA pathophysiology. A prerequisite for the transmigration from the capillary lumen into the perivascular space is the action of MMP-9-expressing monocytes, which first must digest the basal lamina to pave the way for T cells (14) (Figure 2). In the absence of monocytes or macrophages, GCA $\mathrm{T}$ cells fail to invade into $3 \mathrm{D}$ extracellular matrix. The dependence of $\mathrm{T}$ cells on pathogenic monocytes/ macrophages exemplifies the co-occurrence of abnormalities in the innate and adaptive immune system steering inflammatory cells into an immunoprivileged tissue site.

\section{Tissue-Residing CD4 ${ }^{+} \mathrm{T}$ Cells in GCA Lesions}

Lesional $\mathrm{CD}^{+} \mathrm{T}$ cells in the vasculitic wall have two major abnormalities; they are pluripotent effector cells, supporting a multitude of inflammatory effector pathways and they can selfrenew to sustain the wall infiltrates and turn acute vasculitis into chronic-persistent disease (Figures 5 and 6).

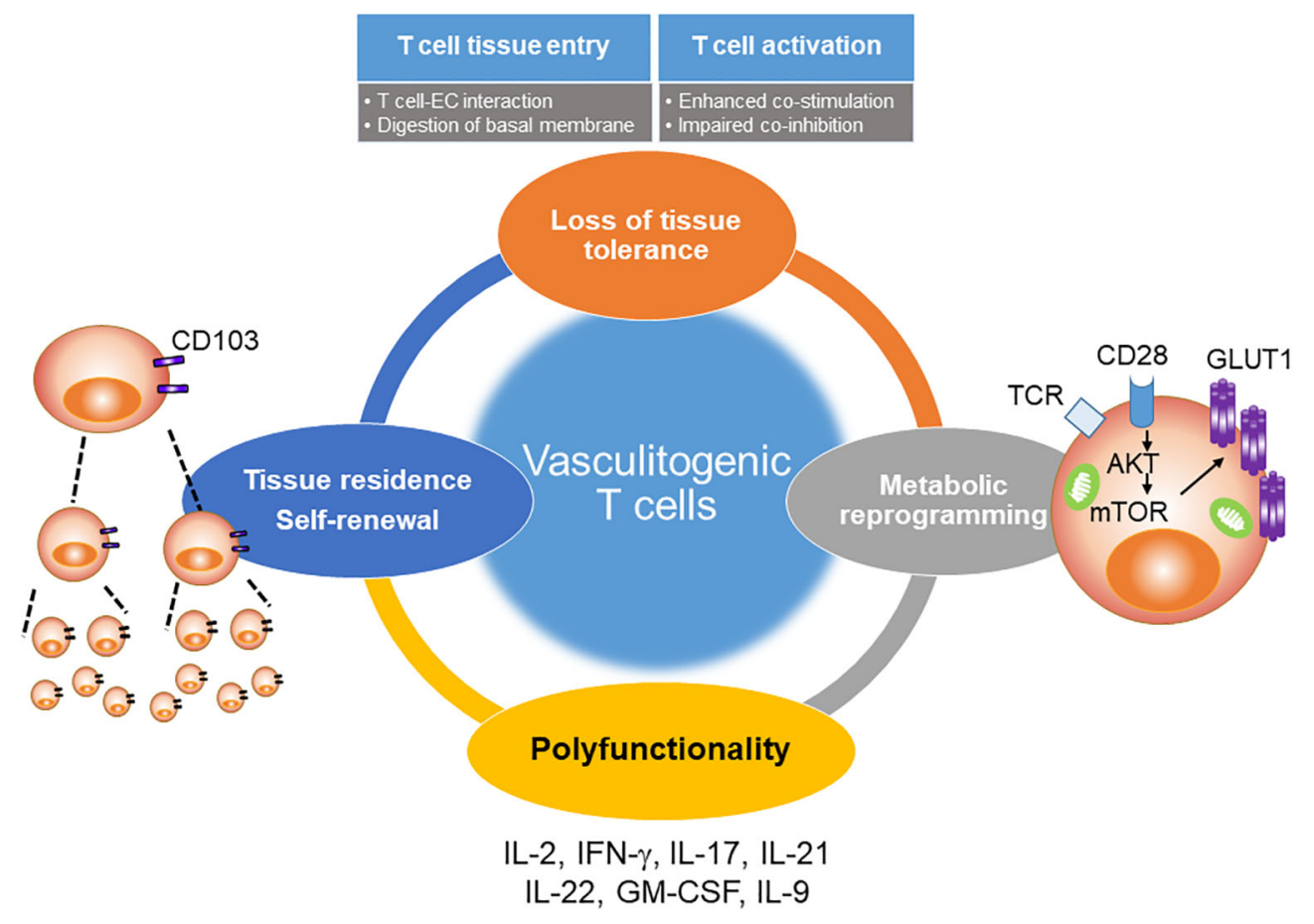

FIGURE 6 | Pathogenic role of T cells in GCA. The shift from protective to pathogenic immunity in GCA involves multiple processes. Four major abnormalities have been molecularly defined (1). In GCA patients, CD4+ T cells aberrantly express NOTCH1, which facilitates T cell-endothelial communication, tissue entry and uncontrolled T cell expansion (2). Excess CD28-dependent signaling imprints a metabolic signature that sustains pro-inflammatory $T$ cells (3). Such T cells supply a multitude of effector cytokine to stimulate macrophages and vascular cells (4). A critical feature of disease-promoting CD4 ${ }^{+} \mathrm{T}$ cells is the ability to establish tissue residency in the vessel wall. Tissue-resident memory $\mathrm{CD}^{+}{ }^{+} \mathrm{T}$ cells render the lesion autonomous and ensure chronicity of disease. 
The vast majority of lesion-residing $\mathrm{CD}^{+} \mathrm{T}$ cells are strongly positive for PD-1 (45) (Figure 5). On human T cells, PD-1 is an activation marker, but more importantly, has been implicated in tumor evasion mechanisms and in exhaustion of chronically stimulated $\mathrm{T}$ cells (74). CD4 ${ }^{+} \mathrm{T}$ cells trapped in the arterial wall are not exhausted, nor are they senescent. Rather, their accumulation is a consequence of insufficiency in PD-L1 expression (see above). Both, vascular DC, and macrophages are distinctly low for PD-L1, disrupting a negative signal to $\mathrm{PD}-1^{+} \mathrm{T}$ cells. The entry of $\mathrm{T}$ cells into the wall and the accumulation/retention of $\mathrm{T}$ cells in the wall are both dependent on PD-L1 (45).

Besides expressing surface $\mathrm{PD}-1$, lesional $\mathrm{CD}^{+}{ }^{+} \mathrm{T}$ cells are polyfunctional (45) (Figure 6). A multitude of $\mathrm{T}$ cell effector cytokines have been mapped to the lesions, including IL-2, IFN$\gamma$, IL-17, IL-21, IL-9, IL-22, and GM-CSF (Figure 6). It has not been clarified whether the polyfunctionality occurs on the level of individual cells or the T cell population. IFN- $\gamma$-producing $\mathrm{CD} 4^{+}$ $\mathrm{T}$ cells represent the dominant $\mathrm{T}$ cell subset in inflamed temporal arteries $(11,75)$. IFN- $\gamma$-producing $\mathrm{CD}^{+} \mathrm{T}$ cells are expanded in the peripheral blood of GCA patients and are resistant to corticosteroid therapy (75). IFN- $\boldsymbol{\gamma}$ has all the characteristics of a critical effector cytokine, as it activates macrophages, DC, and endothelial cells. Interestingly, IFN $-\gamma^{+} \mathrm{CD}^{+} \mathrm{T}$ cells map preferentially to the adventitia of GCA-affected temporal arteries (76). How they guide the activity of the granulomatous infiltrates needs to be clarified. However, the geographical distance to migrating myofibroblasts may be important, as IFN- $\gamma$ is considered to inhibit proliferation of mesenchymal cells.

In contrast to their resistance to corticosteroids, IFN- $\gamma^{+} \mathrm{T}$ cells are dependent on Janus kinase (JAK) and signal transducer and activator of transcription (STAT) signaling and this dependence creates a vulnerability that can be therapeutically exploited. Inhibiting the JAK/STAT signaling pathway with a small molecule inhibitor targeting JAK1/3 is highly effective in suppressing vasculitis, including the IFN- $\gamma$-producing $\mathrm{CD}^{+}{ }^{+} \mathrm{T}$ cells (77). These data have raised the possibility that IFN- $\gamma$ production is part of a feed forward loop, as IFN type II is a potent inducer of JAK/STAT signaling (78). Tissue transcriptomic studies have indicated that STAT target genes are strongly upregulated in the lesions, including target genes of IFN type 1 and type 2 .

IFN- $\gamma$-producing $\mathrm{CD} 4^{+} \mathrm{T}$ cells are accompanied by subsets of lesional T cells that produce IL-17, IL-21, and IL-9 $(79,80)$. Likely, each of these $\mathrm{T}$ cell lineages makes a specialized contribution to the disease process, but mechanistic studies detailing this are not yet available. IL- $17^{+} \mathrm{T}$ cells in GCA lesions have been reported to be highly sensitive to corticosteroid therapy, disappearing upon initiation of this immunosuppressant (75) and are thus different from IFN $-\gamma^{+} \mathrm{T}$ cells, that persist over prolonged periods despite steroid therapy (75). Th17 cells may thus be easily controllable and may not have much value as a therapeutic target.

IL-21-producing $\mathrm{CD}^{+} \mathrm{T}$ cells are abundant in the tissue lesions and in the blood of patients with GCA and appears to be sensitive to glucocorticoid treatment (79). IL-21 is reported to play a role in supporting Th1 and Th17 responses and suppressing $\mathrm{FOXP}^{+} \mathrm{T}$ regulatory cells in GCA (79), but the precise pathogenic role of IL-21 remains unclear.

IL-9 is a pleiotropic cytokine, with the potential to drive both pro-inflammatory and anti-inflammatory responses (81). High expression of IL-9 was reported in temporal artery biopsies (80), but how this cytokine influences vasculitic immune responses is unknown.

IL-22 is believed to mediate the crosstalk between immune cells and stromal cells (82). IL-22 has been encountered in temporal artery biopsies and is strongly linked to vasculitis (83). Little is known so far how stromal cells are involved in the disease process, but they are ultimately important in wall remodeling. Whether IL-22-dependent immunity is relevant in the maladaptive wound healing response awaits clarification.

The $\mathrm{T}$ cell effector cytokine GM-CSF is considered an important regulator of macrophages (84) and could provide effective $\mathrm{T}$ cell-macrophage communication in the granulomatous infiltrates (84). Indeed, macrophages activated by GM-CSF acquire numerous effector functions, enabling them to amplify tissue inflammation. GM-CSF is the product of a specialized $\mathrm{T}$ cell subset that has high disease relevance in multiple sclerosis $(85,86)$.

\section{Tissue-Resident Memory T Cells in the Inflamed Artery}

Despite the physiological ability of host immune protection by trafficking of memory $\mathrm{T}$ cells around the body, recent studies have revealed that specialization of pathogenic memory $\mathrm{T}$ cells into unique tissue-resident subsets may drive regional autoimmunity $(87,88)$. Long-lasting immunity causing temporal artery damage is mediated by tissue resident memory T cells $(44,77)$. Data from reengraftment studies have revealed that vasculitis-causing $\mathrm{T}$ cells acquire tissue residency and build autonomous, self-sufficient inflammatory lesions (77), where repopulation of inflammatory $\mathrm{CD} 4^{+} \mathrm{T}$ cells is maintained from tissue-resident memory populations (Figure 6). Further, metabolic analysis of tissue resident memory $\mathrm{T}$ cells in the vasculitic wall lesions has yielded evidence for high glycolytic activity resulting from CD28-dependent signals and fulfilling the energy demand of repopulating effector $\mathrm{T}$ cells (44). Those tissue-residing T cells are polyfunctional and steroid therapy resistant. In fact, a study analyzing temporal artery biopsies before and up to 12 months after steroid therapy found that half of GCA patients still have ongoing vessel wall inflammation after one year of immunosuppression (13).

\section{CD8 $^{+}$T Cells in GCA}

Early studies examining frequencies of circulating $\mathrm{CD}^{+} \mathrm{T}$ cells in GCA gave rise to the hypothesis that a reduction of $\mathrm{CD}^{+} \mathrm{T}$ cells is typical for active untreated GCA (89). This hypothesis was called into question by later studies (90). A recent manuscript described altered gene expression profiles in blood CD4 and in CD8 T cells in a cohort of 16 GCA patients that were monitored by longitudinal expression profiling (91).

A clue towards an entirely new disease mechanism in GCA CD8 $\mathrm{T}$ cells has come from studying the $\mathrm{T}$ cell aging process. T cell aging leads to a maladaptive response that directly contributes to chronic 
TABLE 2 | Potential therapeutic targets in giant cell arteritis.

\begin{tabular}{|c|c|c|}
\hline Targets & Pathogenic role in vessel wall inflammation & Drugs \\
\hline mTOR signaling & $\begin{array}{l}\text { T cell proliferation and survival; } \\
\text { Metabolic control of } \mathrm{T} \text { cell effector differentiation } \\
\text { and of } \mathrm{T} \text { cell functions; }\end{array}$ & Rapamycin \\
\hline VEGF signaling & $\begin{array}{l}\text { Endothelial cell homeostasis; } \\
\text { Maintenance of vasa vasora; } \\
\text { Pathogenic wall vascularization; } \\
\text { Induction of co-stimulatory ligands (Jagged1); }\end{array}$ & Bevacizumab \\
\hline NOTCH signaling & $\begin{array}{l}\text { T cell fate decisions; } \\
\text { T cell co-stimulation; } \\
\text { T cell clonal expansion and survival; } \\
\text { T cell tissue invasion; } \\
\text { Trafficking of intracellular vesicles; }\end{array}$ & DAPT \\
\hline JAK-STAT signaling & Type I and type II IFN-dependent responses; & $\begin{array}{l}\text { Tofacitinib } \\
\text { Baricitinib }\end{array}$ \\
\hline CD28-AKT signaling & $\begin{array}{l}\text { Uncontrolled co-stimulation; } \\
\text { Metabolic programming of effector T cells; }\end{array}$ & $\begin{array}{l}\text { Abatacept } \\
\text { Anti-CD28 }\end{array}$ \\
\hline PD-1/PD-L1 signaling & $\begin{array}{l}\text { Deficient co-inhibition; } \\
\text { Failure of negative signaling; } \\
\text { Inappropriate T cell expansion, survival and effector functions; }\end{array}$ & $\begin{array}{l}\text { PD-L1 FC } \\
\text { PD1 agonists }\end{array}$ \\
\hline MMP-9 production & $\begin{array}{l}\text { Destruction of the arterial wall tissue barrier; } \\
\text { Structural damage to the vessel wall; }\end{array}$ & MMP-9 blockade \\
\hline
\end{tabular}

inflammatory disease (92). $\mathrm{CD}^{+} \mathrm{T}$ cells are well-known to age faster than $\mathrm{CD}^{+} \mathrm{T}$ cells and a hallmark of $\mathrm{T}$ cell aging is the loss of naïve $\mathrm{CD}^{+} \mathrm{T}$ cells (93). In fact, older individuals fail to generate $\mathrm{CD}^{+} \mathrm{CCR}^{+} \mathrm{T}$ regulatory cells, rendering them susceptible to unopposed immune reactivity (59). Age-dependent decline of protective immunity and rise of dysfunctional immunity may be one of the reasons that GCA occurs exclusively in individuals older than 50 years of age. Indeed, loss-of-function of protective CD8 ${ }^{+}$ Treg cells is associated with aging (59). Mechanistically, CD8 ${ }^{+} \mathrm{T}$ regulatory cells suppress activation and expansion of $\mathrm{CD} 4^{+} \mathrm{T}$ cells by releasing exosomes that contain preassembled NOX2 membrane clusters which are taken up by $\mathrm{CD} 4^{+} \mathrm{T}$ cells (59). Defective $\mathrm{CD} 8^{+} \mathrm{T}$ regulatory cells in GCA patients lose the ability to package NADPH oxidase into immunosuppressive exosomes. A recent study has identified the molecular mechanism leading to $\mathrm{CD}^{+}$Treg cell failure in GCA patients (60). The inability of GCA CD8 ${ }^{+}$Treg cells to release NOX2-containg, immunosuppressive exosomes was mechanistically connected to abnormalities in endosomal trafficking. Specifically, due to aberrant NOTCH4 signaling, GCA $\mathrm{CD}^{+}$Treg cells changed the profile of RAB GTPases, which promoted NOX2 trapping in an intracellular compartment of early and recycling endosomes (60).

These studies have identified a novel molecular abnormality linking $\mathrm{T}$ cell aging, Treg cell failure and susceptibility to vasculitis. Implicating RAB GTPases and intracellular vesicular trafficking in disease pathogenesis opens new conceptual and therapeutic opportunities.

\section{FROM BENCH TO BEDSIDE: POTENTIAL THERAPEUTIC TARGETS IN GCA}

Glucocorticoids (GC) remain the standard therapy, possibly because of their untargeted immunosuppression and the multiplicity of pathogenic pathways contributing to GCA (Figures 2, 5, 6). GC are highly effective in suppressing extravascular GCA, flattening the acute phase response, clinical symptoms, and abnormal laboratory parameters (94). To examine the remission-inducing potential for the vessel wall component of the disease, we have utilized a dual-biopsy approach. 40 patients with a positive temporal artery biopsy received standard doses of prednisone and were rebiopsied on the collateral side at 3, 6, 9 or 12 months (13). About $50 \%$ of patients had active vasculitis after 12 months of GC therapy (13). Patients with a positive second biopsy had excellent clinical and laboratory responses and were clinically indistinguishable from patients in whom the second biopsy was negative. Thus, GC therapy is highly efficient for extravascular GCA and insufficiently treats vascular GCA. Also, clinical assessment and monitoring of sedimentation rate and CRP are not able to assess the inflammatory load in the vessel wall. Overall, new therapeutic approaches are needed to treat GCA, probably in form of combination therapy. The resistance of the vascular component, likely a consequence of the ability of the disease lesions to become autonomous, emphasizes the need for more efficient immunosuppression that can be given over extended time periods in elderly individuals. New therapeutic strategies need to go handin-hand with the development of diagnostic tools that allow quantification of vessel wall inflammation.

Tocilizumab, an anti-IL-6 receptor antibody, has shown efficacy in suppressing ESR and CRP, helping to spare GC dosing to manage the acute phase response (95). However, it remains unknown whether inhibiting IL-6 signaling has beneficial effects on vessel wall inflammation itself. In fact, discrepancies between vascular and extravascular inflammation in large vessel vasculitis has been increasingly recognized and represents the most challenging problem in the management of this autoimmune vasculopathy (96). Disease flares are frequently observed even in GCA patients treated with tocilizumab plus GC 
that have reached normal acute-phase reactant levels. Further, disease progression of local vessel wall inflammation has been reported in patients with Takayasu arteritis on tocilizumab treatment although they were clinically asymptomatic and had normal laboratory findings (97-99). Patients with Kawasaki disease on tocilizumab treatment have been reported to develop giant coronary aneurysms despite clinical and laboratory improvements (100). These data are in line with the concept that correcting downstream inflammatory parameters is insufficient to reset upstream abnormalities in the immune system of the patients. Here, progress made in understanding the immune signaling networks underlying vascular inflammation needs to guide the exploration of novel therapeutic interventions, including those intended to control the inflammatory attack of the vessel wall. One possible approach is to target key effector cells in the vascular lesions, e.g. macrophages. Currently ongoing trials with the GM-CSF receptor blocker mavrilimumab are designed to disrupt the inappropriate macrophage activation in the lesions. An alternative approach is to interfere with disease relevant signaling pathways, which may be shared by several cell populations relevant in the disease process.

Here, we have summarized the signaling pathways that are now understood to contribute to the immunopathogenesis of GCA and may serve as therapeutic targets (Table 2).

\section{mTOR Signaling}

The serine/threonine kinase mTOR (mechanistic target of rapamycin) is designed to integrate environmental signals to coordinate cellular response patterns. mTOR is a critical signaling hub in all cell types relevant for vasculitis, including $\mathrm{T}$ cells, which rely on mTOR activity for their development, differentiation functional fitness. mTOR signaling guides effector cell fate decisions, a fundamental abnormality in $\mathrm{T}$ cells from GCA patients. mTOR has also been implicated in controlling the suppressive activity of regulatory $\mathrm{T}$ cells and regulates the process of $\mathrm{T}$ cell exhaustion. Aberrant $\mathrm{mTOR}$ activation is a hallmark abnormality in $\mathrm{CD}^{+} \mathrm{T}$ cells from GCA patients, both in circulating as well as lesional T cells $(24,101)$. mTOR signaling may also be a driving force in endothelial cells of microvessels that provide access to the vessel wall and function as partners of effector T cells (101). mTOR functions as a sensor of nutrient resources, particularly amino acid supply (102). GCA T cells utilize a highly activated glycolytic program to support their effector functions and sustain their self-replicative potential (44). Inhibiting mTOR signaling may therefore disrupt an array of disease-relevant $\mathrm{T}$ cell functions. The wall remodeling process is dependent on cellular growth and expansion, with multiple cell types involved. mTOR activity may represent a common denominator driving cellular activity of diverse pathogenic population and as such represent a unifying target to treat vasculitis.

\section{VEGF-NOTCH Signaling}

Serum VEGF levels are highly elevated in patients with GCA, indicating the critical role of angiogenesis and endothelial cell function in this autoimmune vasculitis $(21,24)$. Endothelial cells lining the vasa vasorum are the gate keeper of the vessel wall and this barrier has been overcome to enter the tissue niche (8). Also, the remodeling process is particurly dependent on neoangiogenesis within the wall layers. Macrophages, multinucleated giant cells, and mast cells have been identified as a cellular source of VEGF in GCA. VEGF functions not only as an angiogenic factor but also activates endothelial cells, upregulating Jagged1 expression on adventitial vasa vasorum endothelial cells, thus turning the EC into an engaged partner to interact with NOTCH 1 receptor-expressing T cells (24). The surplus of VEGF promotes endothelial cell proliferation and sustains formation of new capillaries $(103,104)$. Anti-VEGF treatment is widely applied in the therapy of malignant tumors and has become a promising treatment to inhibit aberrant neovascularization in ocular disease (105). The NOTCH signaling pathway has been investigated as a therapeutic target to block proliferative activity in malignant cells (106). Here, GCA displays abnormalities that are shared between cancer and autoimmunity, encouraging the exploration of anti-angiogenic and anti-proliferative interventions in GCA. Stopping angiogenesis may have benefit in dampening wall remodeling. Inhibiting $\mathrm{NOTCH}$ signaling may prevent aberrant cellular activation for multiple disease relevant cell populations.

\section{JAK-STAT Signaling}

Transcriptomic analysis has shed light on ongoing JAK-STAT signaling in inflamed temporal arteries, implicating mostly Type I and Type II IFN-dependent responses (77). Type II IFNregulated inflammation is in line with the critical position of IFN- $\gamma$ in disease pathogenesis. Little is known about a potential role of IFN type I. Notably, upregulation of Type I and Type II IFN as upstream inducers of pathogenic immunity has also been reported for Takayasu arteritis (107). We have published a proofof-principle study showing that treatment with tofacitinib, a selective JAK1 and JAK3 inhibitor, is highly efficient in suppressing vessel wall inflammation (77). Unexpectedly, interfering with JAK-STAT signaling was highly successful in interrupting both intimal hyperplasia and wall capillarization in the human artery -SCID chimera model (77). Recently reports suggest that tofacitinib may have a place in managing patients with refractory Takayasu arteritis (108). These data support the concept that autoimmunity in the wall of large arteries relies disproportionally on JAK-STAT signaling and that therapeutic opportunities lie in dampening excessive activity in these fundamental signaling pathways.

\section{T-Cell Co-stimulation and Co-inhibition}

GCA is a granulomatous vasculitis, defining $\mathrm{T}$ cells and macrophages as the key pathogenic drivers. The intensity and duration of $\mathrm{T}$ cell activation is not only dependent on antigen recognition, but equally important are co-stimulatory and coinhibitory signals. Recent data support a role for CD28-mediated co-stimulation in several domains of the disease process, including $\mathrm{T}$ cell expansion, survival, and metabolic fitness. Randomized controlled trials have reported the efficacy and safety of abatacept, CTLA-4Ig, that blocks T cell co-stimulation in patients with GCA (109). However, these clinical trials have 
focused on assessing inflammatory markers (ESR, CRP) and clinical relapses, which all reflect activity in the extravascular arm of GCA. Data are needed to understand whether blocking CD28 co-stimulation has beneficial effects for chronicity of vascular inflammation and the adverse remodeling process of the vascular wall. Proof-of-principle studies in humanized mice are encouraging, emphasizing the dependence of wall inflammation on CD28-mediated co-stimulatory input (44).

Under physiologic conditions, co-stimulatory signals are offset by co-inhibitory signaling. Amongst the inhibitory pathways, the $\mathrm{PD}-1 / \mathrm{PD}-\mathrm{L} 1$ pathway is best known due to the aberrant expression of PD-L1 on tumor cells, which paralyses anti-tumor $\mathrm{T}$ cell responses. The $\mathrm{PD}-1 / \mathrm{PD}-\mathrm{L} 1$ pathway is deficient in GCA due to the low PD-L1 expression on the patients' dendritic cells and macrophages (45). Numerous therapeutic antibodies are in use to disrupt PD-1/PD-L1 signaling in cancer patients, but so far, no therapeutics are available to strengthen PD-1 signaling. Options include agonistic anti-PD-1 antibodies, transferring negative signals into $\mathrm{T}$ cells or replacing the lacking PD-L1 with soluble PD-L1 fused to an Fc domain.

\section{Excess Production of the Metalloproteinase MMP-9}

Breakdown of the basal lamina, enabling the transition of macrophages and $\mathrm{T}$ cells out of the blood stream into the extracellular space of the vessel wall, is an early pathogenic event in GCA and depends on MMP-9-mediating digestion of the protective basal membrane (14). In a preclinical model system, treatment with an antibody blocking MMP9 activity was sufficient to halt vasculitis and prevent vessel wall remodeling (14). An appealing aspect of targeting MMP-9 lies in the potential to stop invasion of the vessel wall while protecting the immunocompetence of the host. MMP-9 was detected in three cell populations: monocytes, macrophages, and multinucleated giant cells. Interfering with the activity of MMP-9 would thus provide opportunities to target innate immunity in GCA, while preserving adaptive immunity. Also, MMP-9 participates in very early steps of autoimmune vasculitis and may be able to terminate invasion of the artery. At the same time, MMP-9 is a key molecule in the destruction of elastic membranes and may be particurly important in complication of GCA aortitis, such as wall dissection and aneurysm formation (14). Finally, MMP-9 blocking agents may be best placed in combination therapies that use a two-pronged approach to have an impact on the complex pathogenesis of GCA.

\section{IL-12/IL-23 Signaling}

A hallmark of GCA is the recruitment and retention of highly differentiated effector $\mathrm{T}$ cells that become part of the granulomas (Figure 5). The differentiation process depends upon lineageinducing cytokines, such as IL-12 and IL-23, which are major regulators of T cell fate. IL-12 and IL-23 have been implicated in promoting Th1 and Th17 lineage commitment in both GCA and Takayasu arteritis $(75,110)$. In situ IL-12 and IL-23 heterodimers have been reported in temporal arteritis lesions (111). In addition, genome-wide association studies have categorized IL$12 \mathrm{~B}$ as a susceptibility gene for Takayasu arteritis $(112,113)$. Ustekinumab, a monoclonal antibody that inhibits both IL-12 and IL-23 signaling by binding to the common p40 subunit, has been tested in patients with GCA and Takayasu arteritis (114, 115). A prospective, open-label trial of ustekinumab in 13 patients with active new-onset or relapsing GCA was prematurely closed because patients could not reach prednisone-free remission (116). Blocking IL-12/IL-23 should interfere with the differentiation program of naïve into memory/ effector $\mathrm{T}$ cells, a process that may precede the onset of vasculitis. Given the autonomy of the vascular lesions (see above tissueresident memory $\mathrm{T}$ cells), interfering with the IL-12/IL-23 pathway may need to be combined with blocking the primary seeding of the vessel wall.

\section{CONCLUSIONS}

Autoimmune disease infrequently targets arteries, but autoimmune vasculitis is a dangerous disease due to the high potential for life-threatening complications. Large arteries, such as the aorta, respond to autoimmune attack with loss of wall integrity, clinically presenting as dissection, aneurysm formation of rupture (Figure 3). In medium arteries, wall inflammation results in a maladaptive remodeling process that occludes the lumen and causes tissue ischemia (Figure 1). The pathologic lesion is a granulomatous reaction, often with formation of multinucleated giant cells (Figures 1 and 3). The molecular signature of disease-relevant monocytes and macrophages includes the aberrant production of the metalloproteinase MMP-9 and the selective loss-of-function of the inhibitory ligand PD-L1. In the vasculitic lesions, macrophages are critical effector cells, supplying cytokines, metalloproteinases and angiogenic factors. The therapeutic targeting of pathogenic macrophage functions is only superficially explored but holds promise to provide entirely new strategies for anti-vasculitic immunotherapy (Figure 2).

As documented by the granulomatous nature of autoimmune vasculitis, GCA is ultimately a disease of misdirected adaptive immunity. The master regulators of the faulty immune response are $\mathrm{CD} 4^{+} \mathrm{T}$ cells that enter a protected tissue niche, take tissue residence, gain autonomy, and differentiate into multiple classes of differentiated effector $\mathrm{T}$ cells (Figure 6). Accordingly, the vasculitic lesions are rich in a spectrum of effector cytokines, including IL-2, IL-9, IL-17, IL-22, GM-CSF, IFN- $\gamma$, and IL-21. Each of these effector cytokines contributes in its own right, multiplying the pathogenic potential of $\mathrm{T}$ cell accumulations forming within the layers of the arterial wall. The multiplicity of effector $\mathrm{T}$ cell populations makes a single causative antigen highly unlikely.

The molecular signature of pathogenic $\mathrm{CD}^{+} \mathrm{T}$ cells in GCA includes the aberrant expression of the NOTCH1 receptor, and the reliance on CD28 costimulatory signaling unopposed by PD1 inhibitory signaling (Figures 2 and 6). GCA patients have metabolically active $\mathrm{CD}^{+} \mathrm{T}$ cells with persistent mTORC1 
activation. These $\mathrm{T}$ cells are powerful drivers of pathogenic cascades that finally lead to wall destruction or to intimal hyperplasia and luminal occlusion. The complexity of GCA pathogenesis offers multiple intersection points that should allow to broaden the diagnostic and therapeutic approach to this difficult-to-manage autoimmune disease (Figure 6; Table2). A major hurdle lies in the split of the disease process into an extravascular and a vascular component which are at least to a large extent independent of each other. Extravascular and vascular GCA follow different trajectories, relate to different pathogenic mechanisms and ultimately, require different diagnostic and therapeutic schemes.

Several unanswered questions remain. How does the aging process of the vessel wall and the immune system conjoin to render the host susceptible to GCA? How does the tissue microenvironment create the stringent tissue tropism of this autoimmune disease? Are there vasculitogenic antigens or is the fundamental abnormality solely a defect in threshold setting of $\mathrm{CD} 4^{+} \mathrm{T}$ cells? How do $\mathrm{CD} 4^{+} \mathrm{T}$ cells engage vascular stromal cells to cause intimal hyperplasia? What is the underlying mechanism driving $\mathrm{T}$ cell polyfunctionality? What are the pathogenic processes underlying extravascular GCA? A new conceptual approach to this autoimmune and autoinflammatory condition will pave the way to the development of novel diagnostic and therapeutic modalities.

\section{REFERENCES}

1. Weyand CM, Goronzy JJ. Clinical practice. Giant-cell arteritis and polymyalgia rheumatica. N Engl J Med (2014) 371(1):50-7. doi: 10.1056/ NEJMcp1214825

2. Weyand CM, Hicok KC, Hunder GG, Goronzy JJ. The HLA-DRB1 locus as a genetic component in giant cell arteritis. Mapping of a disease-linked sequence motif to the antigen binding site of the HLA-DR molecule. J Clin Invest (1992) 90(6):2355-61. doi: 10.1172/JCI116125

3. Carmona FD, Mackie SL, Martín JE, Taylor JC, Vaglio A, Eyre S, et al. A large-scale genetic analysis reveals a strong contribution of the HLA class II region to giant cell arteritis susceptibility. Am J Hum Genet (2015) 96 (4):565-80. doi: 10.1016/j.ajhg.2015.02.009

4. Carmona FD, Vaglio A, Mackie SL, Hernandez-Rodriguez J, Monach PA, Castaneda S, et al. A Genome-wide Association Study Identifies Risk Alleles in Plasminogen and P4HA2 Associated with Giant Cell Arteritis. Am J Hum Genet (2017) 100(1):64-74. doi: 10.1016/j.ajhg.2015.02.009

5. Terao C, Yoshifuji H, Matsumura T, Naruse TK, Ishii T, Nakaoka Y, et al. Genetic determinants and an epistasis of LILRA3 and HLA-B ${ }^{\star} 52$ in Takayasu arteritis. Proc Natl Acad Sci USA (2018) 115(51):13045-50. doi: 10.1073/pnas.1808850115

6. Renauer PA, Saruhan-Direskeneli G, Coit P, Adler A, Aksu K, Keser G, et al. Identification of Susceptibility Loci in IL6, RPS9/LILRB3, and an Intergenic Locus on Chromosome 21q22 in Takayasu Arteritis in a Genome-Wide Association Study. Arthritis Rheumatol (2015) 67(5):1361-8. doi: 10.1002/ art.39035

7. Watanabe R, Hosgur E, Zhang H, Wen Z, Berry G, Goronzy JJ, et al. Proinflammatory and anti-inflammatory $\mathrm{T}$ cells in giant cell arteritis. Joint Bone Spine (2017) 84(4):421-6. doi: 10.1016/j.jbspin.2016.07.005

8. Watanabe R, Berry GJ, Liang DH, Goronzy JJ, Weyand CM. Cellular Signaling Pathways in Medium and Large Vessel Vasculitis. Front Immunol (2020) 11:587089:587089. doi: 10.3389/fimmu.2020.587089

9. Watanabe R, Berry GJ, Liang DH, Goronzy JJ, Weyand CM. Pathogenesis of Giant Cell Arteritis and Takayasu Arteritis-Similarities and Differences. Curr Rheumatol Rep (2020) 22(10):68. doi: 10.1007/s11926-020-00948-x

\section{AUTHOR CONTRIBUTIONS}

MA, JG, and CW wrote the manuscript. SO and GB contributed figures. The concept presented in the manuscript were developed by CW, JG, GB, and DL. All authors contributed to the article and approved the submitted version.

\section{FUNDING}

This work was supported by the National Institutes of Health (R01 AR042527, R01 HL117913, R01 AI108906, R01 HL142068, and P01 HL129941 to CW and R01 AI108891, R01 AG045779, U19 AI057266, and R01 AI129191 to JG) and Merit Review Award I01 BX001669 from the United States (U.S.) Department of Veterans Affairs to JG. The contents do not represent the views of VA or the United States Government. MA was supported by a research fellowship from the Uehara Memorial Foundation.

\section{ACKNOWLEDGMENTS}

Due to space restrictions, not all primary publications could be cited. We apologize to the authors.

10. Weyand CM, Goronzy JJ. Immune mechanisms in medium and large-vessel vasculitis. Nat Rev Rheumatol (2013) 9(12):731-40. doi: 10.1038/ nrrheum.2013.161

11. Weyand CM, Watanabe R, Zhang H, Akiyama M, Berry GJ, Goronzy JJ. Cytokines, growth factors and proteases in medium and large vessel vasculitis. Clin Immunol (2019) 206:33-41. doi: 10.1016/j.clim.2019.02.007

12. Akiyama M, Kaneko Y, Takeuchi T. Tocilizumab in isolated polymyalgia rheumatica: A systematic literature review. Semin Arthritis Rheumatol (2020) 50(3):521-5. doi: 10.1016/j.semarthrit.2019.12.005

13. Maleszewski JJ, Younge BR, Fritzlen JT, Hunder GG, Goronzy JJ, Warrington $\mathrm{KJ}$, et al. Clinical and pathological evolution of giant cell arteritis: a prospective study of follow-up temporal artery biopsies in 40 treated patients. Mod Pathol (2017) 30(6):788-96. doi: 10.1038/ modpathol.2017.10

14. Watanabe R, Maeda T, Zhang H, Berry GJ, Zeisbrich M, Brockett R, et al. MMP (Matrix Metalloprotease)-9-Producing Monocytes Enable T Cells to Invade the Vessel Wall and Cause Vasculitis. Circ Res (2018) 123(6):700-15. doi: 10.1161/CIRCRESAHA.118.313206

15. Nissinen L, Kahari VM. Matrix metalloproteinases in inflammation. Biochim Biophys Acta (2014) 1840(8):2571-80. doi: 10.1016/j.bbagen.2014.03.007

16. Cui N, Hu M, Khalil RA. Biochemical and biological attributes of matrix metalloproteinases. Prog Mol Biol Transl Sci (2017) 147:1-73. doi: 10.1016/ bs.pmbts.2017.02.005

17. Rodriguez-Pla A, Bosch-Gil JA, Rossello-Urgell J, Huguet-Redecilla P, Stone $\mathrm{JH}$, Vilardell-Tarres M. Metalloproteinease 2 and -9 in giant cell arteritis: involvement in vascular remodeling. Circulation (2005) 112(2):264-9. doi: 10.1161/CIRCULATIONAHA.104.520114

18. Sorbi D, French DL, Nuovo GJ, Kew RR, Arbeit LA, Gruber BL. Elevated levels of 92-kd type IV collagenase (matrix metalloproteinase 9) in giant cell arteritis. Arthritis Rheumatol (1996) 39(10):1747-53. doi: 10.1002/ art.1780391019

19. Weyand CM, Wagner AD, Bjornsson J, Goronzy JJ. Correlation of the topographical arrangement and the functional pattern of tissue-infiltrating macrophages in giant cell arteritis. J Clin Invest (1996) 98(7):1642-9. doi: $10.1172 / J C I 118959$ 
20. Rittner HL, Kaiser M, Brack A, Szweda LI, Goronzy JJ, Weyand CM. Tissuedestructive macrophages in giant cell arteritis. Circ Res (1999) 84(9):1050-8. doi: 10.1161/01.RES.84.9.1050

21. Kaiser M, Weyand CM, Bjornsson J, Goronzy JJ. Platelet-derived growth factor, intimal hyperplasia, and ischemic complications in giant cell arteritis. Arthritis Rheumatol (1998) 41(4):623-33. doi: 10.1002/1529-0131(199804) 41:4<623::AID-ART9>3.0.CO;2-6

22. Falke LL, Gholizadeh S, Goldschmeding R, Kok RJ, Nguyen TQ. Diverse origins of the myofibroblast-implications for kidney fibrosis. Nat Rev Nephrol (2015) 11(4):233-44. doi: 10.1038/nrneph.2014.246

23. Kaiser M, Younge B, Bjornsson J, Goronzy JJ, Weyand CM. Formation of new vasa vasorum in vasculitis. Production of angiogenic cytokines by multinucleated giant cells. Am J Pathol (1999) 155(3):765-74. doi: 10.1016/ S0002-9440(10)65175-9

24. Wen Z, Shen Y, Berry G, Shahram F, Li Y, Watanabe R, et al. The microvascular niche instructs $\mathrm{T}$ cells in large vessel vasculitis via the VEGF-Jagged1-Notch pathway. Sci Transl Med (2017) 9(399):eaal3322. doi: $10.1126 /$ scitranslmed.aal3322

25. van Sleen Y, Sandovici M, Abdulahad WH, Bijzet J, van der Geest KSM, Boots $\mathrm{AMH}$, et al. Markers of angiogenesis and macrophage products for predicting disease course and monitoring vascular inflammation in giant cell arteritis. Rheumatol (Oxford) (2019) 58(8):1383-92. doi: 10.1093/ rheumatology/kez034

26. Baldini M, Maugeri N, Ramirez GA, Giacomassi C, Castiglioni A, PrietoGonzález S, et al. Selective up-regulation of the soluble pattern-recognition receptor pentraxin 3 and of vascular endothelial growth factor in giant cell arteritis: relevance for recent optic nerve ischemia. Arthritis Rheum (2012) 64(3):854-65. doi: 10.1002/art.34515

27. Jiemy WF, van Sleen Y, van der Geest KS, Ten Berge HA, Abdulahad WH, Sandovici M, et al. Distinct macrophage phenotypes skewed by local granulocyte macrophage colony-stimulating factor (GM-CSF) and macrophage colony-stimulating factor (M-CSF) are associated with tissue destruction and intimal hyperplasia in giant cell arteritis. Clin Transl Immunol (2020) 9(9):e1164. doi: 10.1002/cti2.1164

28. Akiyama M, Zeisbrich M, Ibrahim N, Ohtsuki S, Berry GJ, Hwang PH, et al. Neutrophil Extracellular Traps Induce Tissue-Invasive Monocytes in Granulomatosis With Polyangiitis. Front Immunol (2019) 10:2617. doi: 10.3389/fimmu.2019.02617

29. Yahagi K, Kolodgie FD, Otsuka F, Finn AV, Davis HR, Joner M, et al. Pathophysiology of native coronary, vein graft, and in-stent atherosclerosis. Nat Rev Cardiol (2016) 13(2):79-98. doi: 10.1038/nrcardio.2015.164

30. Watanabe R, Hilhorst M, Zhang H, Zeisbrich M, Berry GJ, Wallis BB, et al. Glucose metabolism controls disease-specific signatures of macrophage effector functions. JCI Insight (2018) 3(20):e123047. doi: 10.1172/ jci.insight. 123047

31. Shirai T, Nazarewicz RR, Wallis BB, Yanes RE, Watanabe R, Hilhorst M, et al. The glycolytic enzyme PKM2 bridges metabolic and inflammatory dysfunction in coronary artery disease. J Exp Med (2016) 213(3):337-54. doi: 10.1084/jem.20150900

32. Wadstrom K, Jacobsson L, Mohammad AJ, Warrington KJ, Matteson EL, Turesson C. Negative associations for fasting blood glucose, cholesterol and triglyceride levels with the development of giant cell arteritis. Rheumatol (Oxford) (2020) 59(11):3229-36. doi: 10.1093/rheumatology/keaa080

33. Christ A, Gunther P, Lauterbach MAR, Duewell P, Biswas D, Pelka K, et al. Western diet triggers NLRP3-dependent innate immune reprogramming. Cell (2018) 172(1-2):162-75 e 14. doi: 10.1016/j.cell.2017.12.013

34. van der Heijden C, Noz MP, Joosten LAB, Netea MG, Riksen NP, Keating ST. Epigenetics and trained immunity. Antioxid Redox Signal (2018) 29 (11):1023-49. doi: 10.1089/ars.2017.7310

35. van Tuijl J, Joosten LAB, Netea MG, Bekkering S, Riksen NP. Immunometabolism orchestrates training of innate immunity in atherosclerosis. Cardiovasc Res (2019) 115(9):1416-24. doi: 10.1093/cvr/cvz107

36. Riksen NP. Trained immunity and atherosclerotic cardiovascular disease. Curr Opin Lipidol (2019) 30(5):395-400. doi: 10.1097/MOL.000000 0000000628

37. Leon B, Lund FE. Compartmentalization of dendritic cell and T-cell interactions in the lymph node: Anatomy of T-cell fate decisions. Immunol Rev (2019) 289(1):84-100. doi: 10.1111/imr.12758
38. Eisenbarth SC. Dendritic cell subsets in T cell programming: location dictates function. Nat Rev Immunol (2019) 19(2):89-103. doi: 10.1038/ s41577-018-0088-1

39. Pryshchep O, Ma-Krupa W, Younge BR, Goronzy JJ, Weyand CM. Vesselspecific Toll-like receptor profiles in human medium and large arteries. Circulation (2008) 118(12):1276-84. doi: 10.1161/CIRCULATIONAHA. 108.789172

40. Weyand CM, Ma-Krupa W, Pryshchep O, Groschel S, Bernardino R, Goronzy JJ. Vascular dendritic cells in giant cell arteritis. Ann N Y Acad Sci (2005) 1062:195-208. doi: 10.1196/annals.1358.023

41. Krupa WM, Dewan M, Jeon MS, Kurtin PJ, Younge BR, Goronzy JJ, et al. Trapping of misdirected dendritic cells in the granulomatous lesions of giant cell arteritis. Am J Pathol (2002) 161(5):1815-23. doi: 10.1016/S0002-9440 (10)64458-6

42. Ma-Krupa W, Jeon MS, Spoerl S, Tedder TF, Goronzy JJ, Weyand CM Activation of arterial wall dendritic cells and breakdown of self-tolerance in giant cell arteritis. J Exp Med (2004) 199(2):173-83. doi: 10.1084/ jem. 20030850

43. Han JW, Shimada K, Ma-Krupa W, Johnson TL, Nerem RM, Goronzy JJ, et al. Vessel wall-embedded dendritic cells induce T-cell autoreactivity and initiate vascular inflammation. Circ Res (2008) 102(5):546-53. doi: 10.1161/ CIRCRESAHA.107.161653

44. Zhang H, Watanabe R, Berry GJ, Nadler SG, Goronzy JJ, Weyand CM. CD28 Signaling Controls Metabolic Fitness of Pathogenic T Cells in Medium and Large Vessel Vasculitis. J Am Coll Cardiol (2019) 73(14):1811-23. doi: 10.1016/j.jacc.2019.01.049

45. Zhang H, Watanabe R, Berry GJ, Vaglio A, Liao YJ, Warrington KJ, et al. Immunoinhibitory checkpoint deficiency in medium and large vessel vasculitis. Proc Natl Acad Sci USA (2017) 114(6):E970-E9. doi: 10.1073/ pnas.1616848114

46. Ai L, Xu A, Xu J. Roles of PD-1/PD-L1 pathway: signaling, cancer, and beyond. Adv Exp Med Biol (2020) 1248:33-59. doi: 10.1007/978-981-153266-5 3

47. Weyand CM, Berry GJ, Goronzy JJ. The immunoinhibitory PD-1/PD-L1 pathway in inflammatory blood vessel disease. J Leukoc Biol (2018) 103 (3):565-75. doi: 10.1189/jlb.3MA0717-283

48. Brekke LK, Fevang BS, Diamantopoulos AP, Assmus J, Esperø E, Gjesdal CG. Risk of Cancer in 767 Patients with Giant Cell Arteritis in Western Norway: A Retrospective Cohort with Matched Controls. J Rheumatol (2020) 47(5):722-9. doi: 10.3899/jrheum.190147

49. Kermani TA, Schäfer VS, Crowson CS, Hunder GG, Gabriel SE, Ytterberg SR, et al. Malignancy risk in patients with giant cell arteritis: a populationbased cohort study. Arthritis Care Res (Hoboken) (2010) 62(2):149-54. doi: 10.1002/acr.20062

50. Daxini A, Cronin K, Sreih AG. Vasculitis associated with immune checkpoint inhibitors-a systematic review. Clin Rheumatol (2018) 37 (9):2579-84. doi: 10.1007/s10067-018-4177-0

51. Henderson D, Eslamian G, Poon D, Crabb S, Jones R, Sankey P, et al Immune checkpoint inhibitor induced large vessel vasculitis. BMJ Case Rep (2020) 13(5):e233496. doi: 10.1136/bcr-2019-233496

52. Hid Cadena R, Reitsema RD, Huitema MG, van Sleen Y, van der Geest KSM, Heeringa $\mathrm{P}$, et al. Decreased expression of negative immune checkpoint VISTA by CD4+ T cells facilitates $\mathrm{T}$ helper 1, T helper 17 and $\mathrm{T}$ follicular helper lineage differentiation in GCA. Front Immunol (2019) 10:1638. doi: 10.3389/fimmu.2019.01638

53. Chatelain D, Duhaut P, Schmidt J, Loire R, Bosshard S, Guernou M, et al Pathological features of temporal arteries in patients with giant cell arteritis presenting with permanent visual loss. Ann Rheum Dis (2009) 68(1):84-8. doi: 10.1136/ard.2007.084947

54. Ishii K, Mizuuchi T, Yamamoto Y, Mori H, Tago M, Kato E, et al Development of Eosinophilic Temporal Arteritis and Digital Ischemia in a Patient with Hypereosinophilic Syndrome. Intern Med (2020) 59(10):132330. doi: 10.2169/internalmedicine.3707-19

55. Tomizuka T, Kikuchi H, Asako K, Tsukui D, Kimura Y, Kikuchi Y, et al. Is Kimura's disease associated with juvenile temporal arteritis? A case report and literature review of all juvenile temporal arteritis cases. Mod Rheumatol Case Rep (2020) 5(1):123-9. doi: 10.1080/24725625. 2020.1818366 
56. Nadkarni S, Dalli J, Hollywood J, Mason JC, Dasgupta B, Perretti M. Investigational analysis reveals a potential role for neutrophils in giant-cell arteritis disease progression. Circ Res (2014) 114(2):242-8. doi: 10.1161/ CIRCRESAHA.114.301374

57. Wang L, Ai Z, Khoyratty T, Zec K, Eames HL, van Grinsven E, et al. ROSproducing immature neutrophils in giant cell arteritis are linked to vascular pathologies. JCI Insight (2020) 5(20):e139163. doi: 10.1172/jci.insight. 139163

58. Mayranpaa MI, Trosien JA, Nikkari ST, Kovanen PT. Mast cells associate with T-cells and neointimal microvessels in giant cell arteritis. Clin Exp Rheumatol (2008) 26(3 Suppl 49):S63-6.

59. Wen Z, Shimojima Y, Shirai T, Li Y, Ju J, Yang Z, et al. NADPH oxidase deficiency underlies dysfunction of aged CD8+ Tregs. J Clin Invest (2016) 126(5):1953-67. doi: 10.1172/JCI84181

60. Jin $\mathrm{K}$, Wen Z, Wu B, Zhang H, Qiu J, Wang Y, et al. NOTCH-induced rerouting of endosomal trafficking disables regulatory T-cells in vasculitis. J Clin Invest (2020) 22:136042. doi: 10.1172/JCI136042

61. Martinez-Taboada V, Brack A, Hunder GG, Goronzy JJ, Weyand CM. The inflammatory infiltrate in giant cell arteritis selects against B lymphocytes. $J$ Rheumatol (1996) 23(6):1011-4.

62. Graver JC, Boots AMH, Haacke EA, Diepstra A, Brouwer E, Sandovici M. Massive B-Cell Infiltration and Organization Into Artery Tertiary Lymphoid Organs in the Aorta of Large Vessel Giant Cell Arteritis. Front Immunol (2019) 10:83. doi: 10.3389/fimmu.2019.00083

63. Grunewald J, Andersson R, Rydberg L, Gigliotti D, Schaufelberger C, Hansson GK, et al. CD4+ and CD8+ T cell expansions using selected TCR V and J gene segments at the onset of giant cell arteritis. Arthritis Rheum (1994) 37(8):1221-7. doi: 10.1002/art.1780370817

64. Schaufelberger C, Andersson R, Nordborg E, Hansson GK, Nordborg C, Wahlstrom J. An uneven expression of $\mathrm{T}$ cell receptor $\mathrm{V}$ genes in the arterial wall and peripheral blood in giant cell arteritis. Inflammation (2008) 31 (6):372-83. doi: 10.1007/s10753-008-9088-9

65. Weyand CM, Schonberger J, Oppitz U, Hunder NN, Hicok KC, Goronzy JJ. Distinct vascular lesions in giant cell arteritis share identical $\mathrm{T}$ cell clonotypes. J Exp Med (1994) 179(3):951-60. doi: 10.1084/jem.179.3.951

66. Goronzy JJ, Weyand CM. Mechanisms underlying T cell ageing. Nat Rev Immunol (2019) 19(9):573-83. doi: 10.1038/s41577-019-0180-1

67. Sammel AM, Smith S, Nguyen K, Laurent R, Brewer J, Hall N, et al. Assessment for varicella zoster virus in patients newly suspected of having giant cell arteritis. Rheumatol (Oxford) (2020) 59(8):1992-6. doi: 10.1093/ rheumatology/kez556

68. Ostrowski RA, Metgud S, Tehrani R, Jay WM. Varicella Zoster Virus in Giant Cell Arteritis: A Review of Current Medical Literature. Neuroophthalmology (2019) 43(3):159-70. doi: 10.1080/01658107.2019. 1604763

69. Solomon IH, Docken WP, Padera RFJr. Investigating the Association of Giant Cell Arteritis with Varicella Zoster Virus in Temporal Artery Biopsies or Ascending Aortic Resections. J Rheumatol (2019) 46(12):1614-8. doi: 10.3899/jrheum.180912

70. Piggott K, Deng J, Warrington K, Younge B, Kubo JT, Desai M, et al. Blocking the NOTCH pathway inhibits vascular inflammation in largevessel vasculitis. Circulation (2011) 123(3):309-18. doi: 10.1161/ CIRCULATIONAHA.110.936203

71. Sanchez-Martin M, Ferrando A. The NOTCH1-MYC highway toward T-cell acute lymphoblastic leukemia. Blood (2017) 129(9):1124-33. doi: 10.1182/ blood-2016-09-692582

72. Vanderbeck A, Maillard I. Notch signaling at the crossroads of innate and adaptive immunity. J Leukoc Biol (2020). Online ahead of print. doi: 10.1002/ JLB.1RI0520-138R

73. Kelliher MA, Roderick JE. NOTCH Signaling in T-Cell-Mediated AntiTumor Immunity and T-Cell-Based Immunotherapies. Front Immunol (2018) 9:1718. doi: 10.3389/fimmu.2018.01718

74. Ando M, Ito M, Srirat T, Kondo T, Yoshimura A. Memory T cell, exhaustion, and tumor immunity. Immunol Med (2020) 43(1):1-9. doi: $10.1080 / 25785826.2019 .1698261$

75. Deng J, Younge BR, Olshen RA, Goronzy JJ, Weyand CM. Th17 and Th1 Tcell responses in giant cell arteritis. Circulation (2010) 121(7):906-15. doi: 10.1161/CIRCULATIONAHA.109.872903
76. Wagner AD, Björnsson J, Bartley GB, Goronzy JJ, Weyand CM. Interferongamma-producing $\mathrm{T}$ cells in giant cell vasculitis represent a minority of tissue-infiltrating cells and are located distant from the site of pathology. Am J Pathol (1996) 148(6):1925-33.

77. Zhang H, Watanabe R, Berry GJ, Tian L, Goronzy JJ, Weyand CM. Inhibition of JAK-STAT Signaling Suppresses Pathogenic Immune Responses in Medium and Large Vessel Vasculitis. Circulation (2018) 137 (18):1934-48. doi: 10.1161/CIRCULATIONAHA.117.030423

78. Villarino AV, Kanno Y, O'Shea JJ. Mechanisms and consequences of JakSTAT signaling in the immune system. Nat Immunol (2017) 18(4):374-84. doi: 10.1038/ni.3691

79. Terrier B, Geri G, Chaara W, Allenbach Y, Rosenzwajg M, CostedoatChalumeau N, et al. Interleukin-21 modulates Th1 and Th17 responses in giant cell arteritis. Arthritis Rheum (2012) 64(6):2001-11. doi: 10.1002/ art.34327

80. Ciccia F, Rizzo A, Guggino G, Cavazza A, Alessandro R, Maugeri R, et al. Difference in the expression of IL-9 and IL-17 correlates with different histological pattern of vascular wall injury in giant cell arteritis. Rheumatol (Oxford) (2015) 54(9):1596-604. doi: 10.1093/rheumatology/kev102

81. Kaplan MH. Th9 cells: differentiation and disease. Immunol Rev (2013) 252 (1):104-15. doi: 10.1111/imr.12028

82. Sabat R, Ouyang W, Wolk K. Therapeutic opportunities of the IL-22-IL22R1 system. Nat Rev Drug Discovery (2014) 13(1):21-38. doi: 10.1038/ $\operatorname{nrd} 4176$

83. Zerbini A, Muratore F, Boiardi L, Ciccia F, Bonacini M, Belloni L, et al. Increased expression of interleukin-22 in patients with giant cell arteritis. Rheumatol (Oxford) (2018) 57(1):64-72. doi: 10.1093/rheumatology/kex334

84. Wicks IP, Roberts AW. Targeting GM-CSF in inflammatory diseases. Nat Rev Rheumatol (2016) 12(1):37-48. doi: 10.1038/nrrheum.2015.161

85. Galli E, Hartmann FJ, Schreiner B, Ingelfinger F, Arvaniti E, Diebold M, et al. GM-CSF and CXCR4 define a T helper cell signature in multiple sclerosis. Nat Med (2019) 25(8):1290-300. doi: 10.1038/s41591-0190521-4

86. Lotfi N, Thome R, Rezaei N, Zhang GX, Rezaei A, Rostami A, et al. Roles of GM-CSF in the Pathogenesis of Autoimmune Diseases: An Update. Front Immunol (2019) 10:1265. doi: 10.3389/fimmu.2019.01265

87. Mueller SN, Mackay LK. Tissue-resident memory T cells: local specialists in immune defence. Nat Rev Immunol (2016) 16(2):79-89. doi: 10.1038/ nri.2015.3

88. Welten SPM, Sandu I, Baumann NS, Oxenius A. Memory CD8 T cell inflation vs tissue-resident memory $\mathrm{T}$ cells: Same patrollers, same controllers? Immunol Rev (2018) 283(1):161-75. doi: 10.1111/imr.12649

89. Elling P, Olsson A, Elling H. CD8+ lymphocyte subset in giant cell arteritis and related disorders. J Rheumatol (1990) 17(2):225-7.

90. Martinez-Taboada VM, Blanco R, Fito C, Pacheco MJ, Delgado-Rodriguez $\mathrm{M}$, Rodriguez-Valverde $\mathrm{V}$. Circulating $\mathrm{CD} 8+\mathrm{T}$ cells in polymyalgia rheumatica and giant cell arteritis: a review. Semin Arthritis Rheumatol (2001) 30(4):257-71. doi: 10.1053/sarh.2001.9734

91. De Smit E, Lukowski SW, Anderson L, Senabouth A, Dauyey K, Song S, et al. Longitudinal expression profiling of CD4+ and CD8+ cells in patients with active to quiescent giant cell arteritis. BMC Med Genomics (2018) Jul 2311 (1):61. doi: 10.1186/s12920-018-0376-4

92. Goronzy JJ, Weyand CM. Successful and Maladaptive T Cell Aging. Immunity (2017) 46(3):364-78. doi: 10.1016/j.immuni.2017.03.010

93. Moskowitz DM, Zhang DW, Hu B, Le Saux S, Yanes RE, Ye Z, et al. Epigenomics of human CD8 T cell differentiation and aging. Sci Immunol (2017) 2(8):eaag0192. doi: 10.1126/sciimmunol.aag0192

94. Weyand CM, Fulbright JW, Hunder GG, Evans JM, Goronzy JJ. Treatment of giant cell arteritis: interleukin- 6 as a biologic marker of disease activity. Arthritis Rheumatol (2000) 43(5):1041-8. doi: 10.1002/1529-0131(200005) 43:5<1041::AID-ANR12>3.0.CO;2-7

95. Stone JH, Tuckwell K, Dimonaco S, Klearman M, Aringer M, Blockmans D, et al. Trial of Tocilizumab in Giant-Cell Arteritis. N Engl J Med (2017) 377 (4):317-28. doi: 10.1056/NEJMoa1613849

96. Keser G, Aksu K, Direskeneli H. Discrepancies between vascular and systemic inflammation in large vessel vasculitis: an important problem revisited. Rheumatol (Oxford) (2018) 57(5):784-90. doi: 10.1093/ rheumatology/kex333 
97. Sanchez-Alvarez C, Koster M, Duarte-Garcia A, Warrington KJ. Disease progression of Takayasu arteritis in two patients treated with tocilizumab. Ann Rheum Dis (2020) 79(2):e21. doi: 10.1136/annrheumdis-2018-214642

98. Liebling EJ, Peterson R, Victoria T, Burnham JM. Aortic ulceration in a tocilizumab-treated patient with Takayasu arteritis. Ann Rheum Dis (2019) 78(10):e116. doi: 10.1136/annrheumdis-2018-214191

99. Muratore F, Salvarani C. Aortic dilatation in a patient with Takayasu arteritis treated with tocilizumab. Ann Rheum Dis (2019). doi: 10.1136/ annrheumdis-2019-215459. annrheumdis-2019-215459.

100. Nozawa T, Imagawa T, Ito S. Coronary-Artery Aneurysm in TocilizumabTreated Children with Kawasaki's Disease. N Engl J Med (2017) 377 (19):1894-6. doi: 10.1056/NEJMc1709609

101. Maciejewski-Duval A, Comarmond C, Leroyer A, Zaidan M, Le Joncour A, Desbois AC, et al. mTOR pathway activation in large vessel vasculitis. J Autoimmun (2018) 94:99-109. doi: 10.1016/j.jaut.2018.07.013

102. Wolfson RL, Sabatini DM. The Dawn of the Age of Amino Acid Sensors for the mTORC1 Pathway. Cell Metab (2017) 26(2):301-9. doi: 10.1016/ j.cmet.2017.07.001

103. Welti J, Loges S, Dimmeler S, Carmeliet P. Recent molecular discoveries in angiogenesis and antiangiogenic therapies in cancer. J Clin Invest (2013) 123 (8):3190-200. doi: 10.1172/JCI70212

104. Simons M, Gordon E, Claesson-Welsh L. Mechanisms and regulation of endothelial VEGF receptor signalling. Nat Rev Mol Cell Biol (2016) 17 (10):611-25. doi: 10.1038/nrm.2016.87

105. Goel HL, Mercurio AM. VEGF targets the tumour cell. Nat Rev Cancer (2013) 13(12):871-82. doi: 10.1038/nrc3627

106. Chiang MY, Radojcic V, Maillard I. Oncogenic Notch signaling in T-cell and B-cell lymphoproliferative disorders. Curr Opin Hematol (2016) 23(4):36270. doi: 10.1097/MOH.0000000000000254

107. Regnier P, Le Joncour A, Maciejewski-Duval A, Desbois AC, Comarmond C, Rosenzwajg M, et al. Targeting JAK/STAT pathway in Takayasu's arteritis. Ann Rheum Dis (2020). doi: 10.1136/annrheumdis-2019-216900

108. Kuwabara S, Tanimura S, Matsumoto S, Nakamura H, Horita T. Successful remission with tofacitinib in a patient with refractory Takayasu arteritis complicated by ulcerative colitis. Ann Rheum Dis (2020) 79(8):1125-26. doi: 10.1136/annrheumdis-2019-216606

109. Langford CA, Cuthbertson D, Ytterberg SR, Khalidi N, Monach PA, Carette S, et al. A Randomized, Double-Blind Trial of Abatacept (CTLA-4Ig) for the Treatment of Giant Cell Arteritis. Arthritis Rheumatol (2017) 69(4):837-45. doi: 10.1002/art.40044
110. Saadoun D, Garrido M, Comarmond C, Desbois AC, Domont F, Savey L, et al. Th1 and Th17 cytokines drive inflammation in Takayasu arteritis. Arthritis Rheumatol (2015) 67(5):1353-60. doi: 10.1002/art.39037

111. Espigol-Frigole G, Planas-Rigol E, Lozano E, Corbera-Bellalta M, TerradesGarcia N, Prieto-Gonzalez S, et al. Expression and Function of IL12/23 Related Cytokine Subunits (p35, p40, and p19) in Giant-Cell Arteritis Lesions: Contribution of p40 to Th1- and Th17-Mediated Inflammatory Pathways. Front Immunol (2018) 9:809. doi: 10.3389/fimmu.2018.00809

112. Saruhan-Direskeneli G, Hughes T, Aksu K, Keser G, Coit P, Aydin SZ, et al. Identification of multiple genetic susceptibility loci in Takayasu arteritis. Am J Hum Genet (2013) 93(2):298-305. doi: 10.1016/j.ajhg.2013.05.026

113. Terao C, Yoshifuji H, Kimura A, Matsumura T, Ohmura K, Takahashi M, et al. Two susceptibility loci to Takayasu arteritis reveal a synergistic role of the IL12B and HLA-B regions in a Japanese population. Am J Hum Genet (2013) 93(2):289-97. doi: 10.1016/j.ajhg.2013.05.024

114. Terao C, Yoshifuji H, Nakajima T, Yukawa N, Matsuda F, Mimori T. Ustekinumab as a therapeutic option for Takayasu arteritis: from genetic findings to clinical application. Scand J Rheumatol (2016) 45(1):80-2. doi: 10.3109/03009742.2015.1060521

115. Conway R, O’Neill L, Gallagher P, McCarthy GM, Murphy CC, Veale DJ, et al. Ustekinumab for refractory giant cell arteritis: A prospective 52-week trial. Semin Arthritis Rheum (2018) 48(3):523-8. doi: 10.1016/j.semarthrit.2018.04.004

116. Matza MA, Fernandes AD, Stone JH, Unizony SH. Ustekinumab for the treatment of giant cell arteritis. Arthritis Care Res (Hoboken) (2020) Apr5. Online ahead of print. doi: 10.1002/acr.24200

Conflict of Interest: CW was supported by a sponsored research agreement with Kiniksa Pharmaceuticals.

The remaining authors declare that the research was conducted in the absence of any commercial or financial relationships that could be construed as a potential conflict of interest.

Copyright (c) 2021 Akiyama, Ohtsuki, Berry, Liang, Goronzy and Weyand. This is an open-access article distributed under the terms of the Creative Commons Attribution License (CC BY). The use, distribution or reproduction in other forums is permitted, provided the original author(s) and the copyright owner(s) are credited and that the original publication in this journal is cited, in accordance with accepted academic practice. No use, distribution or reproduction is permitted which does not comply with these terms. 